NBER WORKING PAPER SERIES

\title{
WILLINGNESS TO PAY FOR LOW WATER FOOTPRINT FOOD CHOICES DURING DROUGHT
}

\author{
Hannah Krovetz \\ Rebecca Taylor \\ Sofia Villas-Boas \\ Working Paper 23495 \\ http://www.nber.org/papers/w23495 \\ NATIONAL BUREAU OF ECONOMIC RESEARCH \\ 1050 Massachusetts Avenue \\ Cambridge, MA 02138 \\ June 2017
}

We thank the College of Natural Resources at UC Berkeley for financial support in the survey implementation. The views expressed herein are those of the authors and do not necessarily reflect the views of the National Bureau of Economic Research.

NBER working papers are circulated for discussion and comment purposes. They have not been peer-reviewed or been subject to the review by the NBER Board of Directors that accompanies official NBER publications.

(C) 2017 by Hannah Krovetz, Rebecca Taylor, and Sofia Villas-Boas. All rights reserved. Short sections of text, not to exceed two paragraphs, may be quoted without explicit permission provided that full credit, including $\odot$ notice, is given to the source. 
Willingness to Pay for Low Water Footprint Food Choices During Drought

Hannah Krovetz, Rebecca Taylor, and Sofia Villas-Boas

NBER Working Paper No. 23495

June 2017

JEL No. Q18,Q25,Q54,Q51,Q21,M30

\begin{abstract}
$\underline{\text { ABSTRACT }}$
In the context of recent California drought years, we investigate empirically whether consumers are willing to pay for more efficient water usage in the production of four California agricultural products. We implement an internet survey choice experiment for avocados, almonds, lettuce, and tomatoes to elicit consumer valuation for water efficiency via revealed choices. We estimate a model of consumer choices where a product is defined as a bundle of three attributes: price, production method (conventional or organic), and water usage (average or efficient). Varying the attribute space presented to consumers in the experimental choice design gives us the data variation to estimate a discrete choice model - both conditional logit specifications and random coefficient mixed logit specifications. We find that on average consumers have a significant positive marginal utility towards water-efficiency and estimate that there is an implied positive willingness to pay (WTP) of about 12 cents per gallon of water saved on average. Moreover, informing consumers about the drought severity increases the WTP for low water footprint options, but not significantly. We find that there is heterogeneity in the WTP along respondents' education, race, and also with respect to stated environmental concern. Our findings have policy implications in that they suggest there to be a market based potential to nudge consumers who want to decrease their water footprint and follow a more sustainable diet, namely, by revealing information on the product's water footprint in a form of a label. Simulations of removing low water footprint labels from the choice set attributes imply significant consumer surplus losses, especially for the more educated, white, and more environmentally concerned respondents.
\end{abstract}

Hannah Krovetz

Department of Agricultural

\& Resource Economics

University of California, Berkeley

hannah@krovetz.net

Rebecca Taylor

Department of Agricultural

\& Resource Economics

University of California, Berkeley

207 Giannini Hall

Berkeley, CA 94720-3310

becca.taylor@berkeley.edu
Sofia Villas-Boas

Department of Agricultural

\& Resource Economics

University of California, Berkeley

310 Giannini Hall

CA 94720-3310

sberto@berkeley.edu 


\section{Introduction}

In January 2014, the Governor of California declared a Drought State of Emergency, asking all Californians to reduce water consumption by 20 percent. ${ }^{1}$ While droughts are a recurring feature of California's climate, the drought beginning in late 2011 was the driest and warmest drought on record, putting California agriculture under stress (Hanak et al., 2015). ${ }^{2}$ California - a major producer of dairy, tree nuts, fruits, and vegetables - relies heavily on irrigation, much of which is supplied by the state's extensive system of water supply infrastructure - reservoirs, managed groundwater basins, and inter-regional conveyance facilities. ${ }^{3}$ Farmers have taken measures to adapt to drought conditions, such as by shifting towards less water-intensive crop varietals and by adopting more water-efficient irrigation methods (Hanak et al., 2015). ${ }^{4}$ Given the region may increasingly experience high temperatures and low precipitation flows (Mann and Gleick, 2015), is there a market for consumers to compensate farmers for adopting more water efficient production practices?

The rise of eco-labels has created a market for sustainable food options, however, currently a "low water footprint" label is not available to guide consumers who want to decrease the water footprint of their food consumption. Virtual water of an item - defined as the amount of water used during the enire production process, from planting to processing

\footnotetext{
${ }^{1}$ Source: "Governor's Drought Declaration," California Department of Water Resources, Online, accessed Apr. 28, $201 \%$.

${ }^{2}$ In 2015, the drought caused crop revenue losses of up to 902 million dollars, with losses of 250 million dollars in the dairy industry and 100 million dollars in the feedlot industry (Howitt et al., 2015). There is also an increased fallowing of cropland due to lack of water, which is leading to rising food prices (Howitt et al., 2015).

3 "Drought in California," California Department of Water Resources, Online, accessed Apr. 28, $201 \%$.

${ }^{4}$ Climate change and the resulting drought are leading to a new, lower baseline to which the agricultural sector is already adapting.
} 
to distribution - varies greatly across and within California's top grossing agricultural commodities (Mekonnen and Hoekstra, 2011). ${ }^{5}$ Changing consumer dietary habits may have a significant impact on the sustainability of agriculture with regard to water constraints, if consumers choose to purchase more water-efficient options. This paper empirically assesses whether consumers respond to information on the water footprint of the food they choose and tests whether providing additional information on drought severeness sways consumers to choose low water footprint (LWF) food options.

We investigate whether consumers are willing to pay for LWF agricultural products by designing and implementing a choice experiment via an online distributed survey of California consumers. Before the choice experiment, we collect data on respondents' demographic characteristics and stated environmental concern. For the choice experiment, we present the respondents with four food products: avocados, almonds, lettuce, and tomatoes. Within each food product, survey respondents are asked their purchase choice among options that vary by production methods (conventional or organic), water footprint (average or LWF), and price. In addition, we implement an information treatment in the survey design. Half of the respondents are randomly assigned into a treatment group, where they are briefed before the choice experiment about the drought severity in California. The control group is instead taken directly to the choice experiment, without additional information on the drought.

Using the survey data, we estimate a discrete choice model for consumer preferences, where a choice is defined as a bundle of attributes: product type, price, an organic indicator, and a LWF indicator. From the structural demand model parameters, we obtain estimates

\footnotetext{
${ }^{5}$ There is also considerable variation between produce, with nuts and tree fruit being more water intensive than lettuce, for instance. Milk, eggs, beef, and other animal products also use more water on the whole (Mekonnen and Hoekstra, 2011). Thus, it is not surprising that a diet high in animal products (mainly in Europe and the United States) uses $5 \mathrm{~m}^{3}$, or about 1,321 gallons, of water per capita per day, while diets low in animal products require about half (Renault, 2002).
} 
of the willingness to pay (WTP) for the various specified product attributes. In addition, we test whether revealing information on the drought matters for the WTP estimates. We are able to present novel findings in terms of heterogeneity of WTP along the respondents' demographics and their environmental scores and the role of drought information on WTP. Finally, by simulating a variety of changes in the choice set facing consumers, we obtain estimates of counterfactual choices under alternative policy scenarios and calculate the resulting welfare changes, measured as changes in the distribution of consumer surplus. We also relate the individual level changes in consumer surplus to the demographic characteristics of the respondents.

We find that, on average, consumers have a significant positive marginal utility towards water-efficiency and estimate that there is an implied positive willingness to pay for water efficiency of about 11 dollars. This positive WTP means that respondents are on average willing to pay 12 cents for each gallon of water saved, and 9 cents per gallons of water saved in the production of almonds, for example. Moreover, informing consumers about the drought severity increases consumers' WTP for the LWF options, albeit not significantly. We additionally explore heterogeneity in WTP based on consumer characteristics. We find differences in the WTP along respondents' stated environmental concern, which is measured by level of agreement with statements pertaining the environmental issues and policies. There is also significant heterogeneity with respect to education and race. Using counterfactual simulations of removing low water labels and drought information from the choice set attributes, we estimate changes in choices that imply significant consumer surplus losses, especially for the subgroup of respondents that are white, attained higher levels of education, and have higher environmental scores.

The contribution of our paper is twofold: (1) to estimate stated preferences and corresponding WTP for water efficiency in the production of crops, and (2) to investigate whether consumers respond to information about drought severity and the water footprints of prod- 
ucts in their choice sets. The availability of information about a product's attribute, such as water footprint, does not necessarily mean consumers will incorporate it into their decisions and alter their behavior. Our study provides a distribution of WTP estimates for LWF food options during drought years and an empirical test of whether consumers directly incorporate available information. In so doing, we equip resource managers and policymakers with important information on the efficacy of LWF labels as well as a barometer reading on consumer stated preferences.

Related literature investigates avenues and market mechanisms to nudge consumers toward sustainable food products via "eco-labeling," targeting consumers who are willing to pay a premium for a sustainable product (Hallstein and Villas-Boas, 2013). Macdiarmid (2012) found that fewer than $20 \%$ of respondents believed they would know how to make the necessary changes to create a sustainable diet. Smith (2008) discusses how consumers often lack the knowledge or ability to discriminate between what is sustainable and what is not. Tait et al. (2011) found, when evaluating consumer attitudes toward sustainability attributes, that water efficiency is among the most important attribute of a food item, behind price and carbon footprint. Studies have shown that food labeling impacts consumer choices in other settings, such as the USDA organic seal (Kiesel and Villas-Boas, 2007) and expert-opinion wine labels (Hilger et al., 2011).

We follow closely and expand the existing research approaches on consumer-focused mechanisms (such as eco-labels) which use attitudinal and knowledge surveys, consumer choice experiments, and experimental auctions (see e.g., Alfnes et al. 2006; Batte et al. 2003; Johnston et al. 2001). In the revealed and stated preference literature, a variety of reduced form and structural approaches have been used to infer the value consumers place on product attributes that are not observable or tasteable by consumers at the point of purchase (such as organic, vitamin fortified, dolphin-safe, free-range, rBGH-free). In the reduced form context, hedonic price model approaches have been used to estimate relative values for food 
product attributes in a variety of markets (Asche and Guillen, 2012; Roheim, Gardiner, and Asche, Roheim et al.; Roheim et al., 2011; Jaffry et al., 2004; McConnell and Strand, 2000). Structurally, demand system approaches are estimated to place a willingness to pay for product attributes (Teisl et al., 2002). Our work is more closely related to this second literature stream and is the first to use these methods to place a value on water efficiency in the production of the food that consumers choose.

While there are several means of adaptation of agriculture in the context of water constraints and droughts, such as the observed increase in fallowing of irrigated acres, regional crop shifting, and groundwater depletion (Howitt et al., 2015), this paper investigates whether there is willingness to pay for less gallons of water used within crop types. Changing food habits through information and labeling may have a significant impact on the water requirements of agriculture, if consumer react to signals in the marketplace. A higher WTP supports an increase in price for a specific attribute, such as decreased virtual water footprint, because of the additional benefit to the consumer (Abidoye et al., 2011). To our knowledge, there is no empirical evidence on consumer reactions to information on water-use in food production, and this paper fills this gap in the literature. Being able to distinguish food products in the market will enable consumers to act on their values when presented with a choice between a conventional and a sustainable good. Such changes in demand and consumer awareness could spark a major production shift, just as organic agriculture did in the 2000s (Dimitri and Greene, 2002).

The rest of the paper proceeds as follows. Section 2 describes the empirical setting, the research design (i.e. the choice experiment and identification strategies) and summarizes the data. Section 3 outlines the model to estimate consumer choices and willingness to pay for product attributes. Section 4 presents the results of the choice model and discusses the findings in terms of the average and the distribution of WTP in the sample. Section 5 derives the method to perform simulations, and discusses the choice and welfare changes due 
to a counterfactual policy scenario in terms of removing the information on water footprint presented to the respondents. Finally, section 6 concludes and presents avenues of future research.

\section{Empirical Setting, Experimental Design, and Data}

We design and implement a choice experiment, with an information treatment, via an online survey of California consumers. ${ }^{6}$ We collected survey responses from 193 California residents. For each of the respondents, we first asked for information on their demographic characteristics (i.e., gender, age, education, and race). Second, we asked respondents to answer whether they agreed or disagreed with ten environmentally related statements in order to construct a measure of each respondent's environmental score. Finally, we collect data on the respondents' choices among options to purchase four food products: avocados, almonds, lettuce, and tomatoes. These four crops are highly ranked in terms of California's agricultural value and represent approximately 5 percent of California's 25.5 million operated farm acres. ${ }^{7}$ In 2015, California produced over a third of the country's vegetables and two-thirds of the country's fruits and nuts. ${ }^{8}$ Moreover, in 2015, almonds were California's second most valued commodity ( $\$ 5.33$ billion), lettuce was fifth ( $\$ 2.25$ billion), and tomatoes were seventh (1.71 billion). ${ }^{8}$

In addition, we implement an information treatment in the survey design. Half of respondents are randomly assigned into a treatment group, where they are briefed about the

\footnotetext{
${ }^{6}$ The survey company ensured that there is no monetary prize to cause its audience to rush through to complete a survey. Rather, respondents decide which charity they want the survey company to donate for their response.

${ }^{7}$ Source: "2015 State Agriculture Overview," National Agricultural Statistics Service, United States Department of Agricultural, Online, accessed Dec. 21, 2016.

${ }^{8}$ Source: "California Agricultural Production Statistics - 2015 Crop Year Report," California Department of Food and Agriculture, Online, accessed Apr. 28, 2017.
} 
drought severity in California before the choice experiment. The remaining half in the control group gets taken directly to the choice experiment, without information on the drought.

To base the choice experiment on realistic numbers, we collect industry estimates on the virtual water used in avocado, almonds, lettuce, and tomatoes. Recall that the virtual water is defined as the amount of water used per unit of food during its production (Renault, 2002). The average water footprint displayed to survey respondents in our study - in terms of gallons per pound of product produced - is 157 gallons per pound for avocados, 1,715 gallons per pound of almonds, 14.8 gallons per pound for lettuce, and 16.9 gallons per pound of tomatoes.

\subsection{Choices Specification and Experimental Choice Design}

This study uses a discrete choice experiment to evaluate consumer preferences for water footprint as an attribute of food choices and to calculate the difference in WTP between a group treated with additional drought severity information and a control group. ${ }^{9}$ Discrete choice experiments are among the most common methods for gathering stated preference, and are rooted in Random Utility Models (Lu et. al 2013). The first step is to define a product as being made up of a set of attributes. Then respondents are asked to choose a single option, simulating the context that consumers are normally presented with in the marketplace (Tait et al., 2011). There is also a "I would not purchase any of these" option to allow for identification and counterfactual simulations (Gao and Schroeder, 2009; Alfnes

\footnotetext{
${ }^{9}$ See Figures A.1 and A.2 in the Appendix for the survey instrument. The information concerning the drought acts as the treatment, preceding the questions concerning preferences towards water footprint and organic production in food choices (i.e., the treatment information about the drought preceded the avocado first choice question for the treatment group in Figure A.2). The control group performed the choice experiment in Figure A.2 without any additional information.
} 
et al., 2006). ${ }^{10}$

We asked survey respondents to reveal their preferences for five different options within each of four food items - haas avocado, almonds, head lettuce, and tomatoes - as can be seen in Table 1. These items were chosen because avocados and almonds are high-value tree crops that are less adaptable to yearly environmental factors. They require more water than many field crops because the trees need to be maintained and watered year-round. Tomatoes and lettuce represent less permanent, more adaptable crops with lower water footprints. Each food item has three attributes: water footprint, price, and production method (either conventional or organic). Water footprint has two levels, average and low (or "efficient"). Since the production method and water footprint attributes both have two levels, there are $2 \times 2=4$ possible attribute-combinations per item, not counting price. Finally, we use the average price for conventional and organic versions of the products. In the choice options presented in the experiment we add an invented $20 \%$ price premium if the item has efficient water use.

For a random subset of the respondents, additional information on the California drought and its impact on agriculture came before the choice experiment. This information was given to respondents in the form of a short summary statement and an info-graphic highlighting how much water goes into producing different foods. This is defined as the survey treatment. The information concerning the drought and the variation between water intensity of foods acts as a primer, or treatment, preceding the questions concerning preferences towards water efficient and organic product options in the choice experiment. The control group performed the choice experiment without any additional information. By comparing average responses

\footnotetext{
${ }^{10}$ If we do not include an outside option, simulations that increase attributes in a way that the relative ratio of such attributes remains unchanged (such as all prices doubling), will imply that the relative probabilities of choosing the options also remains unchanged, and this is not reasonable if, for example, consumers are budget constrained.
} 
in the treated and control groups, we can test the role of information on the choices and on the estimates of WTP inferred later on via the structural choice model. This is done under the assumption that the control group is a good counterfactual to the treatment group. The next subsection analyzes the balance of treatment and control groups and presents the summary statistics of the data used in the analysis.

\subsection{Survey Data Summary Statistics}

The survey instrument was sent to a total of 208 respondents, where the sample size was determined by financial constraints. Summary statistics of our data set are presented in Table 2. This table is organized in two panels. In Panel A, the demographic makeup of survey respondents in the treatment and control groups is compared to the total California population. In Panel B, we present the share of respondents choosing the organic and lowwater footprint attributes in the treatment and control groups.

In Panel A of Table 2, ages "17 or younger" in the survey sample are underrepresented compared to the California population. Furthermore, the "50-59" and "60 or older" age groups were overrepresented in the survey sample, suggesting the sample data are skewed towards older populations. Similarly, the Panel A shows that education attainment levels of "Less than high school degree" and "High school degree or equivalent" are underrepresented in the survey sample and "Graduate degree" is overrepresented. Income levels in the sample overall are fairly representative of the California population, as is race and gender. When comparing the treatment and control groups, we have a balance across the demographic variables, with the makeup of the control and treatment groups similar for all rows in Panel A. ${ }^{11}$

${ }^{11}$ An illustration of the balance of demographics in the control and treated group is presented in Appendix Figures A.3 and A.4. We cannot reject that the average is similar between control and treated groups for any of the demographic variables. Moreover, we cannot reject the null in a Kolmogorov Smirnov test for 
Turning now to the bottom Panel B of Table 2, we present survey response summary statistics for the share of respondents choosing organic and low water footprint (LWF) options, and the average price of the alternative chosen. The row titled "Organic (share)" represents the fraction of events where a respondent chooses an organic option. A mean of 28 for Total means that survey respondents overall chose organic products $28 \%$ of the time. "LWF (share)" is the fraction of events in which a respondent chooses the lower water footprint option. For the total survey population, a respondent chooses a water efficient option $64 \%$ of the time. Average price is the average of all prices of items chosen, which is $\$ 3.01$. If a respondent choose "I would not purchase any of these" the price is defined as zero. The treatment group has a lower organic choice average than the control group (25\% versus $30 \%)$ and a higher efficient water footprint average choice (66\% versus $63 \%)$. However, the treatment group has a slightly lower average price paid for the chosen alternatives than control group ( $\$ 2.86$ versus $\$ 3.14$ ). The share of the outside option also differs by treatment $(21 \%)$ and control group (17\%).

Next we use the survey data to construct a measure of environmental concern of each respondent based on the degree of agreement/disagreement with a series of ten statements regarding environmental issues and policies. Table 3 lists each of ten statements and reports average survey responses. For each statement, we assign a value of 5 if the response is equal to "Strongly Agree", and equal to 1 if the response is "Strongly Disagree". The measure of environmental concern of each respondent, henceforth called Environmental Score, is the sum of assigned values for all statements. This way, the Environmental Score has a minimum value of 10 if a respondent strongly disagrees with all ten of the environmental statements and a maximum of 50 if the respondent strongly agrees with all of the same ten statements.

equality of distributions between treatment and control groups for Education (p-value 0.936) and Income (p-value 0.481). 
Table 3 shows the average Environmental Score among all respondents is $38.01 .^{12}$

\section{Empirical Strategy to Estimate Willingness to Pay for Product Attributes}

In our analysis on the impact of information on consumer choice, we define product-specific information provision via labels as an additional or differentiated product attribute. Recognizing that consumer products can be defined as a bundle of perceived product attributes provides the framework to compute consumers' willingness to pay for product attributes in a straightforward way.

\subsection{Structural Demand}

The survey data, with respondent-specific choice information and respondents' demographics, enables us to consider and estimate a specification of heterogeneous preferences in an econometric discrete choice model. Starting from a random utility framework (as in McFadden 1974; McFadden and Train 2000; Train 2003 where both the product attributes as well as the random term are assumed to enter linearly, the utility from consuming a certain product can be described as

$$
U_{j i}=X_{j} \beta_{i}+\epsilon_{j i}
$$

\footnotetext{
${ }^{12}$ The bottom right panel of Appendix Figure A.3 shows that the average environmental score is balanced for the treatment and control groups, and, given the confidence intervals, we cannot reject that the averages are similar. Furthermore, when comparing the full distributions in the top left panel of Figure A.4, using kernel density estimates and in a Kolmogorov Smirnov equality of distributions test, a p-value of 0.943 implies that we cannot reject the null of equal distributions for the environmental score of respondents in the treatment and control groups.
} 
The matrix $X_{j}$ therefore indicates attributes of product $j$ and the vector $\beta_{i}$ indicates the marginal utility that individual $i$ places on these attributes as

$$
\beta_{i}=\beta_{0}+\beta_{1} D_{i}
$$

meaning that the coefficients vary according to the respondent's observed demographics $D_{i}$. This implies that we allow for the fact that different decision makers may have different preferences. In this setting, a respondent $i$ chooses the alternative $j$ if it maximizes his utility, that is, if

$$
\operatorname{Pr}\left(\text { Choice }_{j}\right)=\operatorname{Pr}\left(U_{j i}>U_{h i}\right)=\operatorname{Pr}\left(X_{j} \beta_{i}+\epsilon_{j i}>X_{h} \beta_{i}+\epsilon_{h i}\right), \forall h \neq j .
$$

Note that $\epsilon_{i j}$ has a distributional assumption and that assumption drives the econometric model choice. We assume that it is distributed iid extreme value and this results in a conditional logit choice model where we capture preference heterogeneity in that we allow choices of consumer $i$ to be affected by his observable demographics. This is incorporated into the indirect utility formulation as allowing $\beta$ to be a function of $i$ observed demographics $D_{i}$

\subsection{Random Coefficient Logit Choice Model}

If instead we allow that different decision makers may have different preferences - not just due to observable demographics $D_{i}$, which may not capture all the heterogeneity, but due to a more general unobserved heterogeneity structure - then we define the coefficients $\beta_{i}$ to vary according to

$$
\beta_{i}=\beta_{0}+\beta_{2} v_{i}
$$


where $v_{i}$ is a normal random variable capturing any heterogeneity and the price parameter is always a fixed parameter $\alpha=\alpha_{0}$. If there is no heterogeneity in individual preferences relative to the average, then $\beta_{2}$ will be zero. If, however, there is heterogeneity in preferences relative to the average, then $\beta_{2}$ is different from zero. If $\epsilon_{j i}$ are assumed to be independently, identically extreme value distributed (i.e., type I extreme value distributed), the following closed form solution can be derived for the probability that a respondent's product choice corresponds to product $j$ as:

$$
\operatorname{Pr}\left(\text { Choice }_{j}\right)=\operatorname{Pr}\left(U_{j i}>U_{h i}\right)=\operatorname{Pr}\left(X_{j} \beta_{i}+\epsilon_{j i}>X_{h} \beta_{i}+\epsilon_{h i}\right), \forall h \neq j .
$$

These response probabilities constitute a random coefficient logit model if $\beta_{i}$ is specified as (4). This offers flexibility in incorporating consumer heterogeneity with regard to food characteristics such as organic and low water footprint. To recover how $D_{i}$ affects the departure from mean valuations, we then project estimated $\beta_{i}$ on observed demographics $D_{i}$ in a second step as described in the last subsections of this model section.

In a third heterogeneity specification, we define the coefficients $\beta_{i}$ to be combination of the two previous heterogeneity specifications, as

$$
\beta_{i}=\beta_{0}+\beta_{1} D_{i}+\beta_{2} v_{i}
$$

where $v_{i}$ is a normal random variable capturing any random heterogeneity, $D_{i}$ are observed respondents characteristics affecting heterogeneity, and the price parameter is always a fixed parameter $\alpha=\alpha_{0}$. If there is no heterogeneity in individual preferences relative to the average, then $\beta_{1}$ and $\beta_{2}$ will be zero. If, however, there is heterogeneity in preferences due to demographics relative to the average, then $\beta_{1}$ is different from zero, and if there is additional random heterogeneity, then $\beta_{2}$ is different from zero as well. 
Assuming that consumers choose one unit of product $j$ among all the possible products available at a certain time that maximizes their indirect utility, then the probability that good $j$ is chosen is the probability that good $j$ maximizes consumer $i$ 's utility, as in equation (5). If $\epsilon_{j i}$ are assumed to be type I extreme value distributed, the following closed form solution can be derived for the probability that a respondent's product choice corresponds to product $j$ as:

$$
\operatorname{Prob}_{j i}=\frac{e^{X_{j} \beta_{i}+\alpha \text { Price }_{j}}}{\sum_{k=0}^{N} e^{X_{k} \beta_{i}+\alpha \text { Price }_{k}}}
$$

where $\alpha=\alpha_{0}$ is the marginal utility with respect to price, that is constant for all respondents, and $\beta_{i}$ contains the marginal utilities relative to the remaining attributes $X$ for respondent $i$. The mean utility of the option "I would not purchase any of these" presented to a respondent in the choice experiments is normalized to zero. The organic, LWF, and price variables for that alternative in all the experimental choice cases is set equal to zero and this implies that equation (7) becomes

$$
\operatorname{Prob}_{j i}=\frac{e^{X_{j} \beta_{i}+\alpha \text { Price }_{j}}}{1+\sum_{k=1}^{N} e^{X_{k} \beta_{i}+\alpha \text { Price }_{k}}}
$$

These response probabilities constitute a random coefficients mixed logit model with demographics as mixing parameters if $\beta_{i}$ is specified as (6). This choice model offers flexibility in incorporating consumer heterogeneity with regard to food characteristics such as being organic and LWF as a function of $D_{i}$ directly, as well as allowing for random determinants of heterogeneity via $v_{i}$. This modeling approach combined with the unique choice experimental setting and resulting data variation for agricultural food choices allows us to estimate consumers' valuation for water efficiency on average and the complete distribution of valuation of survey respondents (as in Revelt and Train 2000; Huber and Train 2001. To recover how 
$D_{i}$ affects the departure from mean valuations, as before, we project the estimated $\beta_{i}$ on observed demographics $D_{i}$ in a second step as described in the last subsections of this model section.

Finally, given that each respondent makes decisions for the four different products, defining $T=4$ and defining the distribution of the $\theta=(\alpha, \beta)$ parameters in general form as $f\left(\theta \mid \alpha_{0}, \beta_{0}, \beta_{1}, \beta_{2}\right)$, where $\beta$ is specified in equation (4) or (6) and $\alpha=\alpha_{0}$ for all respondents, then the probability of individual $i$ making a sequence of choices among the five alternatives $(j=0, \ldots 4)$ is given as

$$
S_{i}=\int \prod_{t=1}^{T} \prod_{j=0}^{4}\left[\frac{e^{X_{i j t} \beta_{i}+\alpha \text { Price }_{j t}}}{1+\sum_{k=1}^{N} e^{X_{i k t} \beta_{i}+\alpha \text { Price }_{k t}}}\right]^{Y_{i j t}} f\left(\theta \mid \alpha 0, \beta_{0}, \beta_{1}, \beta_{2}\right) d \theta
$$

where $Y_{i j t}=1$ if the respondent $i$ chooses alternative $j$ for situation $t$ and 0 otherwise. Given a total of $I$ respondents, the parameters $\left(\alpha=\alpha_{0}, \beta_{0}, \beta_{1}, \beta_{2}\right)$ are estimated by maximizing the simulated log-likelihood function

$$
S L L=\sum_{i=1}^{I} \ln \left(\frac{1}{R} \sum_{r=1}^{R} \prod_{t=1}^{T} \prod_{j=0}^{4}\left[\frac{e^{X_{i j t} \beta_{i}^{[r]}+\alpha \text { Price }_{j t}}}{1+\sum_{k=1}^{N} e^{X_{i k t} \beta_{i}^{[r]}+\alpha \text { Price }_{k t}}}\right]^{Y_{i j t}}\right)
$$

where $\beta_{i}^{[r]}$ is the $r$-th draw for respondent $i$ from the distribution of $\beta$.

\subsection{Estimating Average and Heterogeneous Marginal Utility and Willingness to Pay}

Using the dataset of product choices, we estimate a random coefficients mixed logit choice model given by equation (8), where each product is defined as a bundle of attributes (i.e., price, an organic dummy, and a LWF dummy) in order to estimate the parameters $\alpha, \beta_{0}, \beta_{1}$, and $\beta_{2}$. Not only can we estimate average marginal utility for a certain attribute $x$, given by $\beta_{0}$, we can also estimate heterogeneity $\beta_{i}$ in the marginal utility for each different respondent 
$i$ in the sample, as given by equation (4) or (6), depending on whether we do not add $D_{i}$ or add $D_{i}$ as mixing parameters into the heterogeneity specification directly, respectively.

To estimate $\beta_{i}$ we proceed as follows. Given that the expected value of $\beta$ conditional on a given response $Y_{i}$ of individual $i$ and a set of alternatives characterized by $X_{i}$ at occasion $t$ is given by

$$
E\left[\beta \mid Y_{i}, X i\right]=\frac{\int \beta \prod_{t=1}^{T} \prod_{j=0}^{4}\left[\frac{e^{X_{i j t} \beta+\alpha \text { Price }_{j t}}}{1+\sum_{k=1}^{N} e^{X_{i k t} \beta+\alpha \text { Price }_{k t}}}\right]^{Y_{i j t}} f\left(\beta \mid \beta_{0}, \beta_{1}, \beta_{2}\right) d \beta}{\int \prod_{t=1}^{T} \prod_{j=0}^{4}\left[\frac{e^{X_{i j t} \beta+\alpha \text { Price }_{j t}}}{1+\sum_{k=1}^{N} e^{X_{i k t} \beta+\alpha \text { rice }_{k t}}}\right]^{Y_{i j t}} f\left(\beta \mid \beta_{0}, \beta_{1}, \beta_{2}\right) d \beta},
$$

then equation (10) can be thought as the conditional average of the coefficient for the subgroup of individuals who face the same alternatives and make the same choices. For each individual $i$ we estimate a certain attribute's $\beta_{i}$ following Revelt and Train (2000) by simulation according to the following:

$$
\hat{\beta}_{i}=\frac{\frac{1}{R} \sum_{r=1}^{R} \beta_{i}^{[r]} \prod_{t=1}^{T} \prod_{j=0}^{4}\left[\frac{e^{X_{i j t} \beta_{i}^{[r]}+\alpha \text { Price }_{j t}}}{1+\sum_{k=1}^{N} e^{X_{i k t} \beta_{i}^{[r]}+\alpha \text { Price }_{k t}}}\right]^{Y_{i j t}}}{\frac{1}{R} \sum_{r=1}^{R} \prod_{t=1}^{T} \prod_{j=0}^{4}\left[\frac{e^{X_{i j t} \beta_{i}^{[r]}}+\alpha \text { Price }_{j t}}{1+\sum_{k=1}^{N} e^{X_{i k t} \beta_{i}^{\beta r]}}+\alpha \text { Price }_{k t}}\right]^{Y_{i j t}}}
$$

where $\beta[r]$ is the $\mathrm{r}$-th draw for individual $i$ from the estimated $i$ 's distribution of $\beta$. The resulting estimates of each respondent's WTP for a particular attribute $x$ are obtained as the ratio of $\beta_{i}$ relative and the marginal utility with respect to price $\alpha$. We can therefore recover not just the average WTP but also the distribution of the WTP in the sample of respondents, and standard errors are obtained using the Delta Method. Finally we relate the estimated willingness to pay $\left(W T P_{i}\right)$ to each respondents' demographics and environmental scores by estimating the equation

$$
W T P_{i}=\gamma_{0}+\gamma_{1} D_{i}+\epsilon_{i}
$$


where $W T P_{i}$ is a vector of all the respondents' individually estimated willingness to pay for LWF alternatives, $D_{i}$ are the demographic characteristics (including the environmental score) of respondent $i$, and $\gamma_{0}, \gamma_{1}$ are parameters to be estimated.

\section{Results}

First we present the results from the choice estimates originating from a conditional logit specification. In this first step, we investigate whether there is significant average stated marginal utility for LWF options as well as stated heterogeneity in the marginal utility as a function of observable characteristics of the respondents, in terms of demographics and environmental score. Second, we explore a more flexible random coefficients choice model allowing for the heterogeneity to vary from the average marginal utility in a random fashion. Third, we include $D_{i}$ as mixing parameters directly and estimate the random coefficients mixed logit model. Given that the conditional logit, as well as the random coefficient logit and the random coefficient mixed logit models, are estimated by maximizing the likelihood and simulated likelihood, respectively, we perform model comparisons using the Akaike information criterion (AIC) among the estimated specifications and discuss the best specification used moving forward.

The average marginal utility as well as each respondents' marginal utility are estimated using simulated maximum likelihood Revelt and Train (2000). The intuition behind the estimation of each respondent's $\beta_{i}$ is that it is computed as a conditional average of $\beta \mathrm{s}$ of respondents similar to them, in that they make similar sequences of choices when presented with the same options in the experimental design and have similar $D_{i}$. Each respondent's WTP for the LWF attribute is then obtained as the ratio between the $\beta_{i}$ and the marginal utility of price $\alpha$.

The variation in estimated individual departures from the average WTP can be either 
purely random or they can be due to the fact that respondents have similar characteristics. This is investigated by correlating the estimated $W T P_{i}$ with respondents' demographics and environmental scores.

\subsection{Conditional Logit Estimates}

In Table 4 we present the estimates of the conditional logit choice model specification where $\beta_{i}$ are given by equation (2). The dependent variable in all of the columns is an indicator variable that is equal to one if an individual chose that alternative and equal to zero otherwise. There are five alternatives to choose from in each of four product groups. All specifications include individual fixed effects controlling for constant characteristics that may affect their choice behavior on average as well as product fixed effects to control constant characteristics of each agricultural product.

In column (1), the right hand side variables are the price, an Organic dummy that is equal to one if the alternative is organic and equal to zero otherwise, an indicator $L W F$ equal to one for if the alternative has a low water footprint and equal to zero otherwise, and interactions Treat $\times$ Organic and Treat $\times L W F$, where Treat is equal to one if the respondent was in the information treatment group. From the estimates in column (1) we see that the coefficient on price is negative and significant, meaning that a high price lowers the marginal utility of purchasing an alternative. The marginal utility of the organic attribute is negative but not significantly different from zero. The LWF attribute has an average marginal utility of 1.272 which is positive and significant. Finally, while being in the treatment group does not imply a higher marginal utility for the LWF attribute, given the non-significant coefficient of the interaction Treat $\times L W F$, being in the treatment group implies a significantly lower marginal utility for the organic attribute, given the negative and significant coefficient of the interaction Treat $\times$ Organic.

In column (2), we further interact demographic characteristics such as age, income, edu- 
cation, gender, and Environmental Score with the variables in column (1). This specification in column (2) allows us to estimate the average marginal utility for all variables in column (1) as well as departures from those averages with respect to the observable characteristics of the respondents. Even though all the lower order terms of triple interactions are included in the specification in column (2), they are not all reported in Table 4 due to space limitations. The number of observation drops in column (2) because not all respondents gave us complete demographic information.

First, we find that the log likelihood increases to -1075 , relative to -1169 in column (1), implying that we explain more of the variation in choices with this specification. Moreover, when comparing models, the second specification is preferred given its lower AIC estimate. Second, the marginal utility of price remains negative and significant. Third, there is heterogeneity for the LWF attribute in specification (2) that the averages in (1) mask, given that several coefficients associated with the interaction of demographics and product attributes are statistically different from zero. In particular, the marginal utility for the LWF attribute increases significantly with the Environmental Score (given the positive and significant coefficient of 0.053), increases with Education (coefficient of 0.430), and increases for White respondents (coefficient of 0.690). None of the other demographics significantly affect the marginal utility with respect to the LWF attribute. Fourth, there is no organic marginal utility heterogeneity. Finally, none of the triple interactions terms, such as Treat $\times L W F \times$ $D_{i}$, are significant for any $D_{i}$. This implies that there is no differential heterogeneity in the treatment group and in the control group in the way respondents value organic or low water footprint options depending on their observable demographics and environmental score.

We next turn to a mixed logit specification - a more flexible choice specification where we allow the average taste parameters to vary randomly for the respondents and not just as a function of a set of observable respondents' characteristics. We also compare the log likelihood of these nested model specifications, and test whether conditioning on demographics, 
or allowing for random heterogeneity, explains more of the observed variation in the choices of different consumers when faced with the survey choice experiment design.

\subsection{Random Coefficients Logit Choice Estimates}

In the first two columns of Table 5 , we present the estimates of the random coefficients logit choice model specification where $\beta_{i}$ are given by equation (4). The dependent variable in all of the columns is an indicator variable that is equal to one if an individual chose that alternative and equal to zero otherwise. There are five alternatives to choose from in each of four product groups. All specifications include respondent fixed effects controlling for constant characteristics that may affect their choice behavior on average. In columns (1) and (2), the right hand side variables are the same as in column (1) of Table 4, however, in column (1) we allow for unobserved random heterogeneity in the two product attributes $L W F$ and Organic and in column (2) we additionally allow the information treatment parameters to have random unobserved heterogeneity by estimating a random coefficient for Treat $\times$ $L W F$ and Treat $\times$ Organic.

The top half of Table 5, labeled "Mean", reports the average estimated marginal utilities. The price coefficient is negative and significant in columns (1) and (2) of Table 5 and in the same magnitude of the marginal utility estimates of price for the conditional logit specifications in Table 4. From the estimates in column (1), we see that the coefficient of price is negative and significant meaning that a high price lowers the marginal utility of purchasing an alternative. The average marginal utility of the organic attribute is negative and significant. The LWF attribute has an average marginal utility of 1.272 which is positive and significant. Finally, being in the treatment group does not imply a higher marginal utility for the low water attribute as well as for the organic attribute, given the non-significant coefficients of the interactions Treat $\times L W F$ and Treat $\times$ Organic.

The bottom half of Table 5, labeled "SD", reports the standard errors of estimated 
marginal utilities. There is significant heterogeneity in the marginal utility of the two attributes given the significant and positive coefficients for the standard errors of the LWF and organic marginal utilities. Table 4 also reports significant heterogeneity based on demographics.

Next, we investigate whether a random coefficient mixed logit presents itself as the preferred specification to move forward in estimating the WTP and performing policy simulations.

\subsection{Random Coefficients Mixed Logit Choice Estimates}

In the third column of Table 5, we present the estimates of the random coefficients mixed logit choice model specification, where $\beta_{i}$ are given by equation (6). In addition to the random coefficients in column (2), in column (3) we additionally allow the demographic characteristics and environmental score to interact with the $L W F$, choosing the interactions that yielded significant coefficients in the conditional logit specification in Table 4. For the mean marginal utilities in column (3), the price coefficient is negative and significant and in the same magnitude of the marginal utility estimates of price for the random coefficients logit in columns (1) and (2), as well as in the same magnitude as the conditional logit specifications in Table 4. As we would expect, this means that a higher price lowers the marginal utility of purchasing an alternative. The mean marginal utility of the organic attribute is negative and significant. The LWF attribute has an average marginal utility of -2.735 , which is negative and significant, and is different from the point estimates in column (1) and (2) since now the $L W F$ attribute is interacted with demographics. To get the average marginal utility for the LWF attribute we need to add the mean coefficient of -2.735 to the coefficient of the demographic interactions times the average demographics, which we do below.

Finally, being in the treatment group does not imply a higher mean marginal utility for the LWF attribute as well as for the organic attribute, given the non-significant coefficients 
of the interactions Treat $\times L W F$ and Treat $\times$ Organic. One possible reason for why the information treatment about the drought was ineffective is that California residents were already aware of the severity of the highly-publicized drought. According to Google trends, web searches for the phrase "California drought" in California have been high since the beginning of $2014 .^{13}$ Providing additional information that consumers already consider when faced with a low water footprint label would not lead to a behavioral response.

Looking at the deviations from the mean marginal utilities, reported in the bottom of Table 5 under the label "SD", there is significant heterogeneity in the marginal utility of the two attributes. This is evidenced by the positive and significant estimates of standard deviations of the LWF and organic marginal utilities.

To interpret the point estimates for the attribute of interest, we obtain the mean marginal utility for the LWF attribute by adding up the mean marginal utility -2.735 with the heterogeneity marginal utility estimated interactions with demographics. ${ }^{14}$ The sum of the average marginal utility $(-2.735)$ and of all the heterogeneity terms equals 1.78 , an estimate that is larger but in the ballpark of the estimates in columns (1) and (2) of Table 5.

Moving forward we choose the model that better predicts the choices made by respondents in our sample using the Akaike information criterion (AIC). The AIC is like a log likelihood ratio test with an extra adjustment in terms of number of regressors in the specifications for different models. When testing between models, we choose the model that has the lowest absolute value of the AIC. We compare all columns of Tables 4 and 5 using the reported AIC. We choose column (3) of Table 5 because it is the model that has the lowest AIC, equal

\footnotetext{
${ }^{13}$ Source: Google Trends, "California Drought" web searches, Online, accessed Apr. 28, 2017.

${ }^{14}$ The heterogeneity part is equal to the marginal utility with respect to environmental score and LWF interaction (0.058) times the average environmental score (35.6), plus the marginal utility with respect to low water footprint and education (0.52) times the average education (3.5, recall that education is classified in increasing levels of school attained, from 1 to 4), plus the marginal utility for white and LWF (0.058) times the share of white respondents $(77 \%)$.
} 
to 984 . In the remainder of this paper, we will use this random coefficient mixed logit as the specification to estimate respondents' distribution of marginal utilities and the distribution of WTP, and to perform counterfactual policy simulations.

\subsection{Willingness to Pay for Low Water Footprint Attribute \& Willingness to Pay for Gallons of Water Saved}

Given the estimated model parameters in column (3) of Table 5, we start by estimating the distribution of the respondents' individual marginal utilities and resulting $W T P_{i}$ with respect to the attribute of interest. Each individual $\beta_{i}$ is estimated given equation (12) and then divided by the marginal utility of price $\alpha$ to obtain each $W T P_{i}$. The top left panel of Figure 1 displays the kernel density of the distribution of $W T P_{i}$ for the LWF attribute and the top right panel breaks up the average estimated WTP for the White subgroup in red and the Non-white subgroup in blue. The two bottom panels relate estimated WTP to two demographic characteristics of the respondents.

We estimate that the average WTP is 11.02 dollars for the LWF attribute. Given that this attribute is associated with an average saving of 90.4 gallons, then the average WTP per gallon saved is $\frac{11.02}{90.4}$ which is equal to 12 cents per gallon of water saved. In particular, we estimate the WTP to be 5.4 cents per gallon in the production of avocados, 9.3 cents per gallon saved in the production of almonds, 48 cents per gallon saved in the production of tomatoes, and 1.3 cents for one gallon of water saved in the production of lettuce.

Furthermore, the estimated distribution of WTP in the top left panel of Figure 1 is not concentrated at the average WTP, suggesting there to be heterogeneity in the value of the LWF attribute. Looking first into race, breaking up the WTP by White and Nonwhite subgroups of respondents does render significant differences in WTP, as we can see in the right panel of Figure 1, where the average for white is higher than for non white respondents. Illustrative evidence in the two bottom panels of Figure 1 suggest that there 
is a positive relationship between the respondents' estimated WTP and the environmental score of respondents, as well as a positive relationship between the estimated WTP and the respondents' increasing degree of education attained. When sorting individuals by increasing environmental score on the horizontal axis, we fit an upwards sloping linear OLS model estimate from regressing WTP and environmental score, as depicted by the fitted values in the upwards sloping red line in the bottom left panel of Figure 1. The same happens for the scatter plot of WTP and education levels as shown in the bottom right panel data scatter plot and upwards sloping linear fitted values.

Heterogeneity in the WTP is formally investigated by estimating equation (13), a linear regression of the estimated individual WTP and the characteristics of the respondents. The estimates are reported in Table 6. While income, age, and gender are not significantly correlated with the WTP for the low water option, a respondents' stated level of education and environmental score both are positively correlated with WTP. The white subgroup of the respondents also have a significantly higher WTP than their non-white counterparts.

\section{Choice Changes and Welfare Changes in Counterfactual Policy Simulations}

Finally, we ask the counterfactual question of what would happen to respondents' choices and to consumer welfare, ceteris paribus, were there to be no low water footprint information revealed to consumers. To answer this question, we perform simulations and compute the maximizing utility choices for each respondent in this counterfactual scenario. With that we are able to simulate respondents new choices and estimate the distribution of changes in respondent's consumer surplus. To assess who loses and who wins, we project the changes in consumer surplus on respondents' demographics and environmental scores in the final step. 


\subsection{Simulating Respondents Counterfactual Choices}

For each counterfactual scenario we keep respondents' preferences unchanged, which in practice means that the marginal utility parameters are not changing from the baseline model pre-simulation. To estimate choices given the model parameters, we estimate the probabilities of each alternative being chosen in each case (avocado, almonds, lettuce, and tomato) by all respondents, given the data on the attributes pre-simulation as in equation (8). In so doing, we obtain the predicted pre-simulation baseline choices for all respondents. Then, we change the vector or vectors of attributes under the counterfactual scenario considered,

defined as $\tilde{X}$, and recompute the probabilities that each respondent would make under this scenario for all cases, using the new attributes in equation (8). For example, simulating no low water footprint labels means that all products are indistinguishable in this counterfactual scenario along the LWF attribute, which means in practice that $X_{i j, L W F}=0, \forall i, j$, which also implies that all interactions with that attribute are zero in the scenario.

\subsection{Estimating Consumer Welfare Changes in Policy Simulations}

Estimates of changes in consumer surplus (CS) are derived through simulation of consumer choices under counterfactual compositions of their attribute choice sets. These correspond to a respondent's compensating variation for a change in product attributes (Small and Rosen, 1981). The expected consumer surplus, $C S_{i}$, is defined as

$$
C S_{i}=\frac{1}{|\alpha|} \ln \sum_{j} e^{X_{j} \beta_{i j}-\text { oprice }_{j}}
$$

where $\alpha$ denotes the marginal utility of price. We estimate the consumer surplus for the choices as they are and for the best alternative when the LWF attribute is removed and there is also no longer an information treatment on the respondents. Changes in consumer 
surplus are then obtained for each respondent. We estimate the average change in consumer surplus as well as how changes in consumer surplus are related to respondents' individual demographic characteristics and environmental score by estimating the following equation

$$
\Delta(C S)_{i}=\delta_{0}+\delta_{1} D_{i}+\epsilon_{i}
$$

where $\Delta(C S)_{i}$ is a vector of all the respondents' individually estimated changes in CS for the policy simulation of no experimental treatment and no LWF label, $D_{i}$ are the demographic

characteristics (including the environmental score) of respondent $i$, and $\delta_{0}, \delta_{1}$ are parameters to be estimated.

\subsection{Policy Simulation of Removing Low Water Footprint and Drought Information}

First we estimate the predicted average probabilities of the choices for each of the five alternatives given the estimated parameters of column (3) in Table 5. These are depicted in the left panel of Figure 2 with the confidence intervals for each alternative. Recall that alternative 1 (A1) is the conventional and average water footprint option, alternative 2 (A2) is conventional and low water footprint, alternative 3 (A3) is organic and average water footprint, alternative 4 (A4) is organic and low water footprint, and alternative 5 (A5) is none of the above.

In the baseline, all the average predicted probabilities are statistically significantly different from each as given by the confidence intervals in Figure 2. The option most chosen, as predicted by the model, is A2 (conventional and LWF). The next option is A4 (organic and LWF). The third most chosen is the outside option, A5 (none of the above). The least chosen option is the A3 (organic and average water footprint).

When simulating the counterfactual choices of removing the treatment and LWF labels from the information set of the respondents, the average predicted probabilities change 
significantly relative to the baseline, as given by the right panel of Figure 2. Now, the most chosen option is not to select any of the four options, namely A5. A2 and A4 (the LWF options) drop significantly relative to baseline. A3's probability of being chosen is now significantly different from zero as respondents switched from A4 towards A3. This is because both A3 and A4 are organic, A3 is cheaper than A4, and now there is no reason to buy A4 given that the LWF label is not available as differentiation. The same happens for A1 and A2-A2 drops relative to baseline and A1 increases as A1 is cheaper than A2 and both are conventional products. In terms of welfare, since the outside option increases so much and its utility is normalized to zero, it is expected that those consumers that switch to A5 have a lower utility than before. We investigate formally the changes in respondents' consumer surplus by comparing the baseline and the counterfactual scenario's compensated variation for all respondents.

Figure 3 presents the estimated changes in consumer surplus for the respondents when they are faced with the same five options but A2 and A4 are no longer identified as low water footprint and they are no longer given an information treatment on the drought. The top left panel of this figure depicts the kernel density of the distribution of changes in consumer surplus for all respondents. Most of the consumers lose, given that most of the mass is below 0 , some respondents stay the same, while a small proportion of the distribution covers positive welfare changes. Overall, the visual evidence suggests that this policy experiment has a net welfare loss.

In the remaining panels of Figure 3, we relate the changes in simulated consumer surplus to respondents' characteristics. The top right panel shows an almost flat but slightly negative fitted linear regression of changes in consumer surplus with respondent's environmental scores. In the left bottom panel it appears that the average change in consumer surplus is more negative for lower educated subgroups than for higher educated subgroups, although those differences are not statistically different from each other. In the bottom right we also 
see a non-linear relationship between respondent's income and respondent's average change in consumer surplus.

We test whether there are significant heterogeneous changes in consumer surplus by estimating equation (13). These estimates are reported in Table 7 . On average respondents lose 3.35 dollars in terms of surplus from this policy experiment. Given that the average price of the chosen option is about 3 dollars, this is a large loss and corresponds to the most action being driven by consumers who switch to the outside option of not consuming anything. The findings in Table 7 are consistent with the graphical correlations in the top right and bottom panels of Figure 3. Higher education and being white are negatively and significantly correlated with consumer surplus losses. A higher environmental score is correlated with a larger consumer surplus loss, although the negative point estimate is economically very small and not significant. Respondents' income is uncorrelated with consumer surplus losses given the insignificant coefficient associated with increases in income.

From the top left panel of Figure 3, we identify a large proportion of respondents who lose and also a smaller proportion of respondents who do not lose in this policy experiment. To understand this heterogeneity, Figure 4 breaks up the baseline choices (top panels) and simulated predicted choices (bottom panels) for those who have a net loss (left panels) and for those who do not (right panels). We can now see that the ones who have no welfare losses (right panels) were those respondents whose preferred alternative was A5 (i.e., none of the others), then A1 and A3, and lastly A2 and A4, which are the LWF options. It is therefore not surprising that welfare does not drop for these consumers due to the policy. Welfare actually increases slightly for these respondents due to random factors affecting utility. In the left panels, the net losers were those consumers who preferred A2 and A4 and due to the policy had the largest inconvenience and had to make significantly different choices from the top left to the bottom left panel.

Finally, we estimate that total welfare drops given that the sum of changes in consumer 
surplus is -749.2 for the losers and 3.77 for the non-losers in the survey sample. Given that the sample is more educated, has higher income, and is more white than the California average, and because we find greater consumer surplus losses for those that are white, educated, and wealthier, we may be overestimating the welfare losses in California. We re-weight each consumer surplus change estimate to reflect the California distribution of income, race, and education and recompute the total change in the re-weighted change in consumer surplus. The histogram of changes in consumer surplus for the survey sample (in red) and the histogram of changes in consumer surplus for the re-weighted California (in blue) are depicted in Figure 5. We see that, most of the mass of the re-weighted histograms for income (top left), education (top right), age (bottom left) and race (bottom right), shifts to the right, meaning that the sample was indeed overstating the welfare losses relative to the CA population. We obtain a total net loss of -237 dollars when re-weighting by income, -268 when re-weighting by education, -323 when re-weighting by age, and -415 when re-weighting to match the race distribution in California. While these are all lower estimates of welfare losses than the sample estimate of -745 , they are significantly different then zero.

\section{Conclusion}

In the context of recent California drought years, we investigate empirically whether consumers are willing to pay for more efficient water usage in the production of four California agricultural products. We implement an internet survey choice experiment for avocados, almonds, lettuce, and tomatoes to elicit consumer valuation for water efficiency via revealed choices. We estimate a model of consumer demand where a product is defined as a bundle of three attributes: price, production method (conventional or organic), and water usage (average or efficient). Varying the attribute space presented to consumers in the experimental choice design gives us the data variation to estimate a discrete choice model based on a 
conditional logit specification and a random coefficient mixed logit specification. In so doing, this paper provides researchers and policymakers with the first estimates of the distribution of WTP for low water footprint food options during drought years. In addition, we test whether revealing information on the drought matters for the WTP.

We find that, on average, there is an implied positive willingness to pay for water efficiency of about 11 dollars. In terms of gallons of water saved, this means that respondents are on average willing to pay 12 cents for each gallon of water saved in the production of food. Moreover, when informing consumers about the drought severity, this increases consumer's WTP for the LWF options, albeit not significantly. Having additional information of consumer demographic characteristics, we find that there is heterogeneity in the WTP along respondents' stated environmental concern. There is also significant heterogeneity with respect to education and race. Using counterfactual simulations of removing water footprint and drought information from the attribute choice set, we estimate changes in choices that imply significant consumer surplus losses, especially for respondents reporting higher levels of attained education and environmental score, and for white respondents.

The consumer valuation estimates provide insights into the policy debate regarding how to label and present food products (Lee and Hatcher, 2001) in California and in a future of water scarcity. The WTP far exceeds the cost of one gallon of water sold to agriculture, which ranges from 0.5 cents to 0.3 cents in California during drought years, ten times as much as during non-drought years. ${ }^{15}$ While a comprehensive cost-benefit analysis also requires data on the cost (possibly involving technological changes) of saving one gallon of water used in production, our findings have policy implications in that they suggest there to be at least a demand-side, market-based potential to nudge consumers who want to decrease their water

${ }^{15}$ Estimates obtained by using the reported costs to farmers ranging from $\$ 1,000$ to $\$ 1,800$ per cubic acre, and given that one cubic acre corresponds to 325,851 gallons. Source: "California Water Prices Soar for Farmers as Drought Grows," Bloomberg, Online, accessed Apr. 28, $201 \%$. 
footprint and follow a more sustainable diet.

Our present paper offers valuable insights into the effectiveness of revealing information on a product's water footprint in a form of a label and on educating consumers about water constraints in the production of the food they buy (i.e., drought severity). However, there are three potential weaknesses: (1) we have captured consumers' stated preferences and not actual behaviors, (2) the small sample size, and (3) the non-representativeness of the sample for the California population. Following field studies and methodologies implemented in our own previous work (Hilger et al., 2011), and given that there can be disparities between consumers' stated preferences and their actual purchases (Hensher and Bradley, 1993; Batte et al., 2007), future work should extend the experimental approach into a retail-level consumer field study - using actual choices rather than survey choices to assess consumer

responses and valuations for water efficiency and based on a larger and more representative sample. Furthermore, future work should repeat the survey during non-drought years, given that the WTP estimates may be different if the analysis is performed in years when water is perceived to be more plentiful.

\section{References}

Abidoye, B. O., H. Bulut, J. Lawrence, B. Mennecke, and A. M. Townsend (2011). US Consumers' Valuation of Quality Attributes in Beef Products. Journal of Agricultural and Applied Economics 43(1), 1-12.

Alfnes, F., A. Guttormensen, G. Steine, and K. Kolstad (2006). Consumer's Willingness to Pay for the Color of Salmon: A Choice Experiment with Real Economic Incentives. American Journal of Agricultural Economics 88(4), 1050-1061.

Asche, F. and J. Guillen (2012). The Importance of Fishing Method, Gear and Origin: The Spanish Hake Market. Marine Policy 36(2), 365-369. 
Batte, M., J. Beaverson, and N. Hooker (2003). Organic Food Labels: A Customer Intercept Survey of Central Ohio Food Shoppers.

Batte, M., N. Hooker, T. Haab, and J. Beaverson (2007). Putting Their Money Where Their Mouths Are: Consumer Willingness to Pay for Multi-ingredient, Processed Organic Food Products. Food Policy 32(2), 145-149.

Dimitri, C. and C. Greene (2002). Recent Growth Patterns in the US Organic Foods Market. Agriculture Information Bulletin 777. Washington DC: US Department of Agriculture, Economic Research Service.

Gao, Z. and T. Schroeder (2009). Effects of Label Information on Consumer Willingness-toPay for Food Attributes. American Journal of Agricultural Economics 91 (3), 795-809.

Hallstein, E. and S. B. Villas-Boas (2013). Can Household Consumers Save the Wild Ffish? Lessons from a Sustainable Seafood Advisory. Journal of Environmental Economics and Management 66(1), 52-71.

Hanak, E., J. Mount, C. Chappelle, J. Lund, J. Medellin-Azuara, P. Moyle, and N. Seavy (2015). What If California's Drought Continues? Public Policy Institute of California. Aug. 2015. Online. Accessed Apr. 28, 2017.

Hensher, D. and M. Bradley (1993). Using Stated Response Data to Enrich Revealed Preference Discrete Choice Models. Marketing Letters 4(2), 139-152.

Hilger, J., G. Rafert, and S. Villas-Boas (2011). Expert Opinion and the Demand for Experience Goods: An Experimental Approach in the Retail Wine Market. Review of Economics and Statistics 93(4), 1289-1296.

Howitt, R., J. Medellín-Azuara, D. MacEwan, J. Lund, and D. Sumner (2015). Economic 
Analysis of the 2015 Drought for California Agriculture. UC Davis Center for Watershed Sciences.

Huber, J. and K. Train (2001). On the Similarity of Classical and Bayesian Estimates of Individual Mean Partworths. Marketing Letters 12(3), 259-269.

Jaffry, S., H. Pickering, Y. Ghulam, D. Whitmarsh, and P. Wattage (2004). Consumer choices for quality and sustainability labelled seafood products in the uk. Food Policy 29(3), 215228.

Johnston, R. J., C. Wessells, H. Donath, and F. Asche (2001). Measuring Consumer Preferences for Eco-labeled Seafood: An International Comparisons. Journal of Agricultural and Resource Economics 26(1), 20-39.

Kiesel, K. and S. B. Villas-Boas (2007). Got Organic Milk? Consumer Valuations of Milk Labels after the Implementation of the USDA Organic Seal. Journal of Agricultural and Food Industrial Organization 5(1).

Lee, K. H. and C. B. Hatcher (2001). Willingness to Pay for Information: An Analyst's Guide. The Journal of Consumer Affairs 35(1), 120-139.

Macdiarmid, J. (2012). Is a Healthy Diet an Environmentally Sustainable Diet? Proceedings of the Nutrition Society 72(1), 13-20.

Mann, M. and P. Gleick (2015). Climate Change and California Drought in the 21st Century. Proceedings of the National Academy of Sciences 112(3), 3858-3859.

McConnell, K. E. and I. E. Strand (2000). Hedonic Prices for Fish: Tuna Prices in Hawaii. American Journal of Agricultural Economics 82(1), 133-144.

McFadden, D. (1974). The Measurement of Urban Travel Demand. Journal of Public Economics 3(4), 303-328. 
McFadden, D. and K. Train (2000). Mixed MNL Models for Discrete Response. Journal of Applied Econometrics 15(5), 447-470.

Mekonnen, M. M. and A. Y. Hoekstra (2011). The Green, Blue and Grey Water Footprints of Crops and Derived Crop Products. Hydrology and Earth System Sciences 15(5), 15771600.

Renault, D. (2002). Value of Virtual Water in Food: Principles and Virtues. Presented at the UNESCO-IHE Workshop on Virtual Water Trade, 12-13 Dec. 2002, Delft, the Netherlands.

Revelt, D. and K. Train (2000). Customer-specific Taste Parameters and Mixed Logit: Households' Choice of Electricity Supplier. Working Paper No. E00-274, Department of Economics, UCB.

Roheim, C. A., F. Asche, and J. I. Santos (2011). The Elusive Price Premium for Ecolabelled Products: Evidence from Seafood in the UK Market. Journal of Agricultural Economics 62(3), 655-668.

Roheim, C. A., L. Gardiner, and F. Asche. Value of Brands and Other Attributes: Hedonic Analysis of Retail Frozen Fish in the UK. Marine Resource Economicsv, volume=.

Small, K. and H. Rosen (1981). Applied Welfare Economics with Discrete Choice Models. Econometrica 49(1), 105-130.

Smith, B. G. (2008). Developing Sustainable Food Supply Chains. Philosophical Transactions of the Royal Society: Biological Sciences 363(1492), 849-861.

Tait, P., S. Miller, W. Abell, W. Kaye-Blake, M. Guenther, and C. Saunders (2011). Consumer Attitudes towards Sustainability Attributes on Food Labels. Presented at the 55th Annual AARES National Conference, Melbourne, Victoria. 
Teisl, M., B. Roe, and R. Hicks (2002). Can Eco-labels Tune a Market? Evidence from Dolphin Safe Labeling. Journal of Environmental Economics and Management 43(3), $339-359$.

Train, K. (2003). Discrete Choice Methods with Simulation. Cambridge university press. 
Table 1: Choice Set Design: Production Method, Water Footprint, and Price

\begin{tabular}{lccc}
\hline Product & Production Method & Water footprint & Price $(\$ / \mathrm{lb})$ \\
\hline Hass Avocado & Conventional & Average $(157 \mathrm{gal} / \mathrm{lb})$ & 0.98 \\
& Organic & Average $(157 \mathrm{gal} / \mathrm{lb})$ & 2.00 \\
& Organic & Efficient $(80 \mathrm{gal} / \mathrm{lb})$ & 2.40 \\
& Conventional & Efficient $(80 \mathrm{gal} / \mathrm{lb})$ & 1.18 \\
Almond & Conventional & Average $(1,715 \mathrm{gal} / \mathrm{lb})$ & 5.99 \\
& Organic & Average $(1,715 \mathrm{gal} / \mathrm{lb})$ & 11.59 \\
& Organic & Efficient $(1,450 \mathrm{gal} / \mathrm{lb})$ & 13.90 \\
& Conventional & Efficient $(1,450 \mathrm{gal} / \mathrm{lb})$ & 7.19 \\
Lettuce (Head) & & & \\
& Conventional & Average $(14.8 \mathrm{gal} / \mathrm{lb})$ & 2.17 \\
& Organic & Average $(14.8 \mathrm{gal} / \mathrm{lb})$ & 5.00 \\
& Organic & Efficient $(5.9 \mathrm{gal} / \mathrm{lb})$ & 6.00 \\
& Conventional & Efficient $(5.9 \mathrm{gal} / \mathrm{lb})$ & 2.60 \\
& & & \\
Tomatoes (Fresh) & Conventional & Average $(16.9 \mathrm{gal} / \mathrm{lb})$ & 1.56 \\
& Organic & Average $(16.9 \mathrm{gal} / \mathrm{lb})$ & 1.99 \\
& Organic & Efficient $(6.5 \mathrm{gal} / \mathrm{lb})$ & 2.39 \\
& Conventional & Efficient $(6.5 \mathrm{gal} / \mathrm{lb})$ & 1.87 \\
\hline
\end{tabular}

Note: For each item there are two levels of variety (conventional or organic), two levels of water footprint (average and efficient), and four price levels to portray the four combinations of production method and water footprint. For all products, an option "I would not purchase any of these" was also given to respondents. 
Table 2: Summary Statistics

\begin{tabular}{|c|c|c|c|c|c|}
\hline \multicolumn{6}{|c|}{ Panel A. Demographics } \\
\hline & & California & Treated Group & Control Group & Total \\
\hline & & Population* & Respondents & Respondents & Respondents \\
\hline \multirow[t]{2}{*}{ Gender } & Male & 49.7 & 53.06 & 52.29 & 52.66 \\
\hline & Female & 50.3 & 46.94 & 47.71 & 47.34 \\
\hline \multirow[t]{3}{*}{ Age } & 17 or younger & 24.4 & 1.83 & 2.04 & 1.93 \\
\hline & $18-59$ & 59.3 & 66.06 & 66.33 & 66.18 \\
\hline & 60 or older & 16.3 & 32.11 & 31.63 & 31.88 \\
\hline \multirow[t]{3}{*}{ Education } & Less than some college & 60.4 & 27.78 & 37.76 & 32.52 \\
\hline & Associate degree, Bachelor degree & 27.8 & 31.48 & 29.59 & 30.58 \\
\hline & Graduate degree or more & 11.8 & 40.74 & 32.65 & 36.89 \\
\hline \multirow[t]{3}{*}{ HH Income } & $\$ 49,000$ or less & 41.5 & 26.42 & 31.25 & 28.71 \\
\hline & $\$ 50,000-\$ 99,999$ & 28.9 & 30.19 & 29.17 & 29.70 \\
\hline & $\$ 100,000$ or more & 29.4 & 43.40 & 39.58 & 41.58 \\
\hline \multirow[t]{2}{*}{ Race } & White (including Hispanic) & 57.6 & 83.64 & 76.53 & 80.29 \\
\hline & Black, Asian, and other minorities & 42.4 & 16.36 & 23.47 & 19.71 \\
\hline Number of Observ. & & 38.8 million & 110 & 98 & 208 \\
\hline
\end{tabular}

Panel B. Summary Statistics of Survey Responses

\begin{tabular}{lccc} 
& $\begin{array}{c}\text { Treated Group } \\
\text { Respondents }\end{array}$ & $\begin{array}{c}\text { Control Group } \\
\text { Respondents }\end{array}$ & $\begin{array}{c}\text { Total } \\
\text { Respondents }\end{array}$ \\
\hline Organic (share) & 25.26 & 30.45 & 28.00 \\
LWF (share) & 65.56 & 62.50 & 63.94 \\
None of the options (share) & 20.92 & 17.05 & 18.87 \\
Average price of chosen options & 2.86 & 3.14 & 3.01 \\
\hline
\end{tabular}

Note* $^{*}$ Source for the California Data: 2014 CA Census Fact Finder Database. 


\section{Table 3: Response Summary Statistics for Ten Statements underlying Environmental Score}

\begin{tabular}{lr}
\hline Statement & Average (Standard Error) \\
\hline 1. Climate change is a result of human activities and is already affecting people worldwide. & $4.05(0.089)$ \\
2. Protecting the environment should be given utmost priority, & $3.81(0.084)$ \\
even if it causes slower economic growth and some loss of jobs. & $3.45(0.097)$ \\
3. It is the government's responsibility to impose high taxes on fossil fuels. & $3.97(0.087)$ \\
4. The U.S. government should impose stricter laws on pollution. & $3.19(0.096)$ \\
5. People should pay higher prices to address climate change. & $3.80(0.092)$ \\
6. There should be more investment using tax dollars in alternative fuels. & $4.20(0.074)$ \\
7. People should make lifestyle changes to reduce environmental damage. & $3.74(0.083)$ \\
8. It is important to purchase things that are more environmentally friendly, & $3.83(0.085)$ \\
even at a greater cost. & \\
9. The current generation has a responsibility to protect the environment & $3.96(0.081)$ \\
for future generations, even if it leaves themless well off. & $38.01(0.720)$ \\
10. Personal food choices can affect the environmental impact of agriculture & \\
\hline
\end{tabular}


Table 4: Conditional Logit Choice Estimates

\begin{tabular}{|c|c|c|}
\hline & $\begin{array}{c}\text { (1) } \\
\text { Condit. Logit }\end{array}$ & $\begin{array}{c}(2) \\
\text { Condit. Logit }\end{array}$ \\
\hline Price & $\begin{array}{c}-0.139^{* * *} \\
(0.019)\end{array}$ & $\begin{array}{c}-0.146^{* * *} \\
(0.020)\end{array}$ \\
\hline Organic & $\begin{array}{l}-0.164 \\
(0.120)\end{array}$ & $\begin{array}{l}-0.152 \\
(0.123)\end{array}$ \\
\hline LWF & $\begin{array}{c}1.272^{* * *} \\
(0.109)\end{array}$ & $\begin{array}{c}-2.382^{* * *} \\
(0.440)\end{array}$ \\
\hline Treat $\times$ LWF & $\begin{array}{c}0.179 \\
(0.148)\end{array}$ & $\begin{array}{l}0.297^{*} \\
(0.161)\end{array}$ \\
\hline Treat $\times$ Organic & $\begin{array}{l}-0.297^{*} \\
(0.160)\end{array}$ & $\begin{array}{l}-0.285^{*} \\
(0.164)\end{array}$ \\
\hline $\mathrm{Env} \times \mathrm{LWF}$ & & $\begin{array}{c}0.053^{* * *} \\
(0.008)\end{array}$ \\
\hline $\mathrm{Edu} \times \mathrm{LWF}$ & & $\begin{array}{c}0.430^{* * *} \\
(0.108)\end{array}$ \\
\hline White $\times$ LWF & & $\begin{array}{c}0.690^{* * *} \\
(0.188)\end{array}$ \\
\hline Num of Obs. & 4160 & 3960 \\
\hline Log Likelihhod & -1168.959 & -1074.598 \\
\hline $\mathrm{AIC}$ & 2347.919 & 2165.195 \\
\hline Product FE & Yes & Yes \\
\hline Respondent FE & Yes & Yes \\
\hline
\end{tabular}

Note: Robust standard errors in parentheses. $* p<0.10$, $* * p<0.05, * * * p<0.01$. The table displays the estimates of conditional logit regressions where the dependent variable is equal to one if an alternative out of 5 is chosen and equal to zero otherwise. Organic $=1$ for organic choices. $L W F$ $=1$ for low water footprint choices, that is, the more efficient characteristic. Treat $=1$ if the respondent received the information treatment. Specification (2) also includes the interaction of $L W F$ and respondent characteristics. Only the significant coefficients are reported due to space in column (2). Respondents' AIC reports the Akaike's Information criterion for model specification testing. 
Table 5: Random Coefficient and Mixed Logit Choice Estimates

\begin{tabular}{|c|c|c|c|}
\hline & $\begin{array}{c}(1) \\
\text { Random Coeff. Logit }\end{array}$ & $\begin{array}{c}(2) \\
\text { Random Coeff. Logit }\end{array}$ & $\begin{array}{c}\text { (3) } \\
\text { Mixed Logit }\end{array}$ \\
\hline \multicolumn{4}{|l|}{ Mean } \\
\hline Price & $\begin{array}{c}-0.191^{* * *} \\
(0.023)\end{array}$ & $\begin{array}{c}-0.191^{* * *} \\
(0.023)\end{array}$ & $\begin{array}{c}-0.194^{* * *} \\
(0.024)\end{array}$ \\
\hline Organic & $\begin{array}{l}-0.683^{* *} \\
(0.305)\end{array}$ & $\begin{array}{c}-0.637^{* *} \\
(0.301)\end{array}$ & $\begin{array}{c}-0.685^{* *} \\
(0.317)\end{array}$ \\
\hline LWF & $\begin{array}{c}1.546^{* * *} \\
(0.191)\end{array}$ & $\begin{array}{c}1.516^{* * *} \\
(0.179)\end{array}$ & $\begin{array}{c}-2.735^{* * *} \\
(0.674)\end{array}$ \\
\hline Treat $\times$ Organic & $\begin{array}{l}-0.518 \\
(0.421)\end{array}$ & $\begin{array}{l}-0.646 \\
(0.492)\end{array}$ & $\begin{array}{l}-0.665 \\
(0.505)\end{array}$ \\
\hline Treat $\times$ LWF & $\begin{array}{c}0.252 \\
(0.267)\end{array}$ & $\begin{array}{c}0.325 \\
(0.281)\end{array}$ & $\begin{array}{c}0.391 \\
(0.255)\end{array}$ \\
\hline Env $\times$ LWF & & & $\begin{array}{c}0.058^{* * *} \\
(0.013)\end{array}$ \\
\hline $\mathrm{Edu} \times \mathrm{LWF}$ & & & $\begin{array}{c}0.521^{* * *} \\
(0.169)\end{array}$ \\
\hline White $\times$ LWF & & & $\begin{array}{c}0.822^{* * *} \\
(0.299)\end{array}$ \\
\hline \multicolumn{4}{|l|}{ SD } \\
\hline LWF & $\begin{array}{c}1.427^{* * *} \\
(0.174)\end{array}$ & $\begin{array}{c}1.250^{* * *} \\
(0.223)\end{array}$ & $\begin{array}{c}0.998^{* * *} \\
(0.212)\end{array}$ \\
\hline Organic & $\begin{array}{r}2.409^{* * *} \\
(0.279)\end{array}$ & $\begin{array}{r}2.270^{* * *} \\
(0.345)\end{array}$ & $\begin{array}{l}2.362^{* * *} \\
(0.349)\end{array}$ \\
\hline Treat $\times$ Organic & & $\begin{array}{c}1.197 \\
(1.014)\end{array}$ & $\begin{array}{l}1.316 \\
(0.957)\end{array}$ \\
\hline Treat $\times$ LWF & & $\begin{array}{l}1.088^{* *} \\
(0.513)\end{array}$ & $\begin{array}{l}0.841^{*} \\
(0.465)\end{array}$ \\
\hline Num of Obs. & 4160 & 4160 & 3960 \\
\hline Log Likelihood & -1059.665 & -1058.920 & -983.592 \\
\hline AIC & 2133.329 & 2135.841 & 1991.184 \\
\hline Respondent FE & Yes & Yes & \\
\hline
\end{tabular}

Note: Robust standard errors in parentheses. $* p<0.10, * * p<0.05, * * * p<0.01$. The table displays the estimates of mixed logit regressions where the dependent variable is equal to one if an alternative out of 5 is chosen and equal to zero otherwise. Organic $=1$ for organic choices. $L W F=1$ for low water footprint choices. Treat $=1$ if the respondent received the information treatment. AIC reports the Akaike's information criterion for model specification testing. 
Table 6: Regression of Respondents' Mixed Logit WTP Estimates on Demographics

\begin{tabular}{lc}
\hline & $(1)$ \\
& WTP for $L W F$ Characteristic \\
\hline Env & $0.304^{* * *}$ \\
& $(0.037)$ \\
Income & 0.195 \\
& $(0.289)$ \\
Educ & $2.403^{* * *}$ \\
& $(0.465)$ \\
Age & -0.078 \\
& $(0.218)$ \\
Female & 0.709 \\
& $(0.623)$ \\
White & $4.277^{* * *}$ \\
& $(0.739)$ \\
Constant & $-12.814^{* * *}$ \\
& $(1.610)$ \\
\hline Num of Obs. & 193 \\
R squared & 0.530 \\
\hline Note: Robust standard errors in parentheses. $* p<0.10, * * p<0.05, * * * p<0.01$
\end{tabular}


Table 7: Regression of Change in Consumer Surplus Estimates on Demographics

\begin{tabular}{lc}
\hline & $(1)$ \\
& Change in CS \\
\hline Env & $-0.142^{* * *}$ \\
& $(0.005)$ \\
Income & -0.012 \\
& $(0.032)$ \\
Educ & $-1.057^{* * *}$ \\
& $(0.091)$ \\
Age & -0.042 \\
& $(0.034)$ \\
Female & -0.036 \\
& $(0.097)$ \\
White & $-1.933^{* * *}$ \\
& $(0.128)$ \\
Constant & $7.045^{* * *}$ \\
& $(0.470)$ \\
\hline Num of Obs. & 193 \\
R squared & 0.929 \\
\hline Note: Change in consumer estimates from simulation of removing $L W F$ option. \\
Robust standard errors in parentheses. $* p<0.10, * * p<0.05, * * * p<0.01$
\end{tabular}


Figure 1: Estimated WTP for Low Water Attribute, for Entire Sample and by Respondent Characteristics
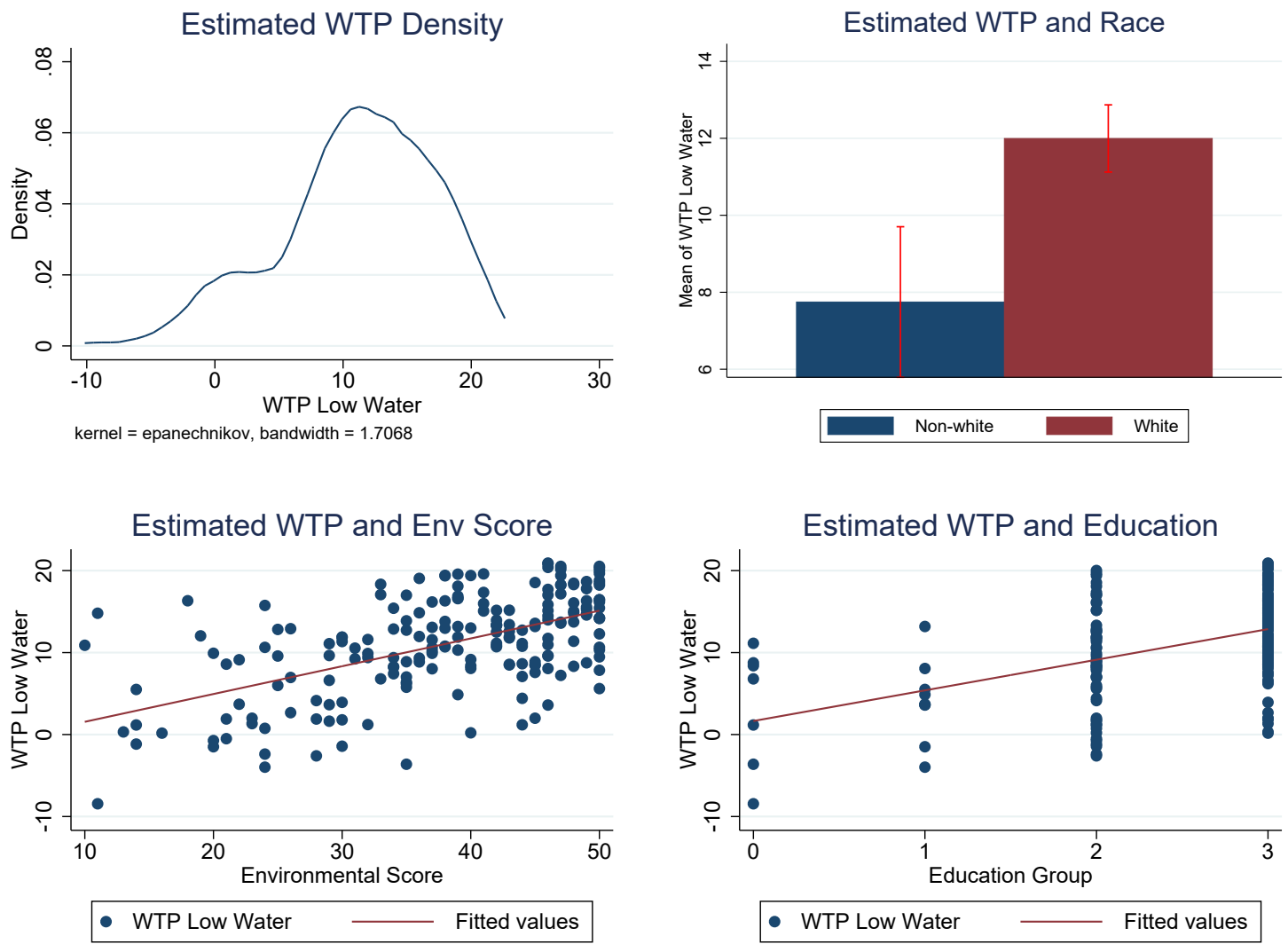

Note: The figure displays the kernel density of the distribution of estimated WTP for the LWF attribute and then relates the estimated WTP for respondents to the respondents' demographics. Estimates based on mixed logit choice specification with demographics and random coefficients. Education is considered into four ranges: Education=1 if "Less than high school degree," Education=2 if "High school degree or equivalent (e.g., GED)," Education=3 if "Some college but no degree or Associate degree," and finally, Education=4 if "Bachelor degree or Graduate degree." 
Figure 2: Estimated Probability of Choosing an Alternative, With and Without Low Water Footprint Attribute
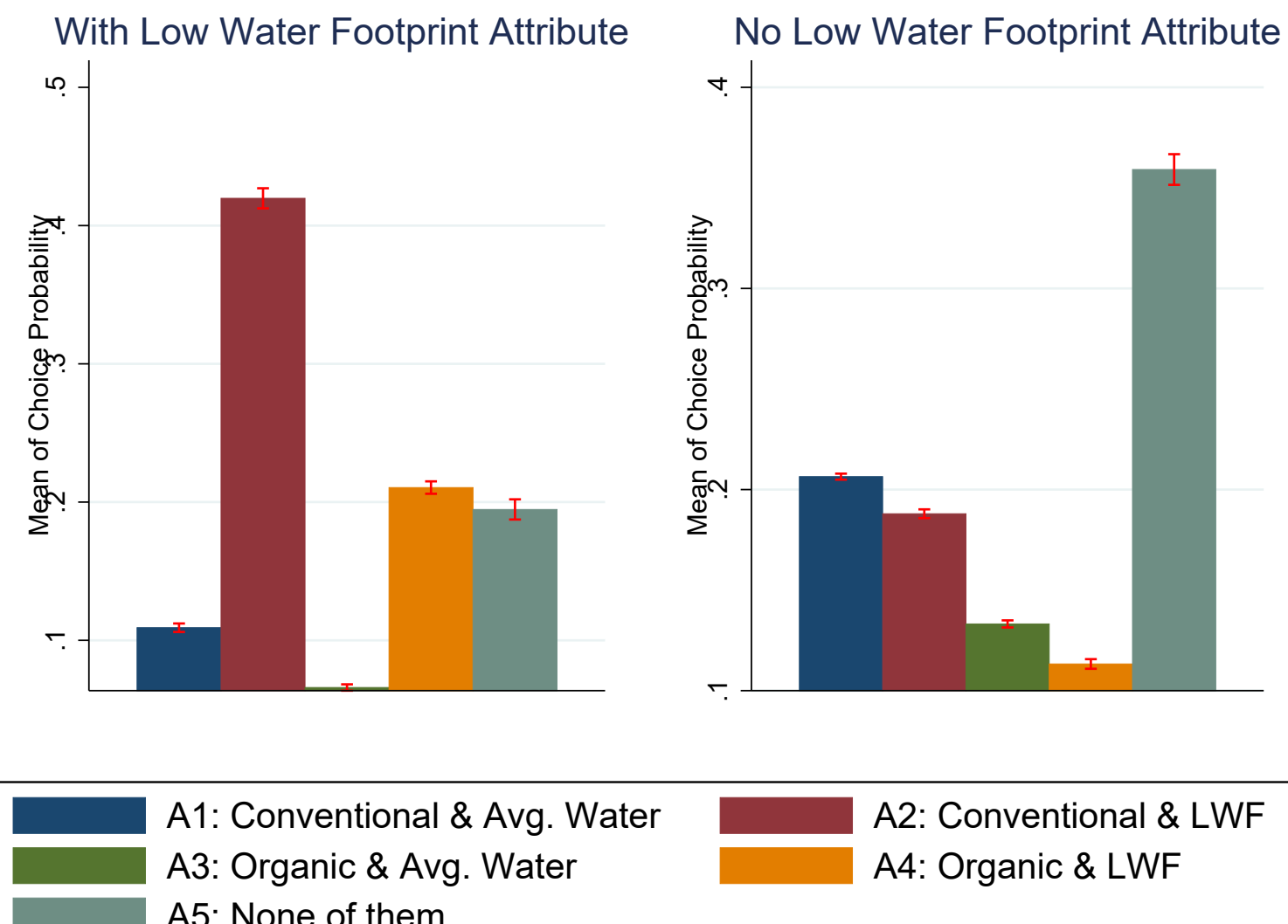

A1: Conventional \& Avg. Water

A3: Organic \& Avg. Water

A5: None of them

Note: The figure displays the average estimated probabilities, and confidence intervals, of choosing the 5 alternatives with and without LWF attribute. Estimates are based on the random coefficients mixed logit choice specification with demographics and random coefficients. The five alternatives are: (1) conventional and average water; (2) conventional and low water; (3) organic and average water; (4) organic and low water; (5) none of them. 
Figure 3: Estimated Change in Consumer Surplus With and Without Low Water Attribute
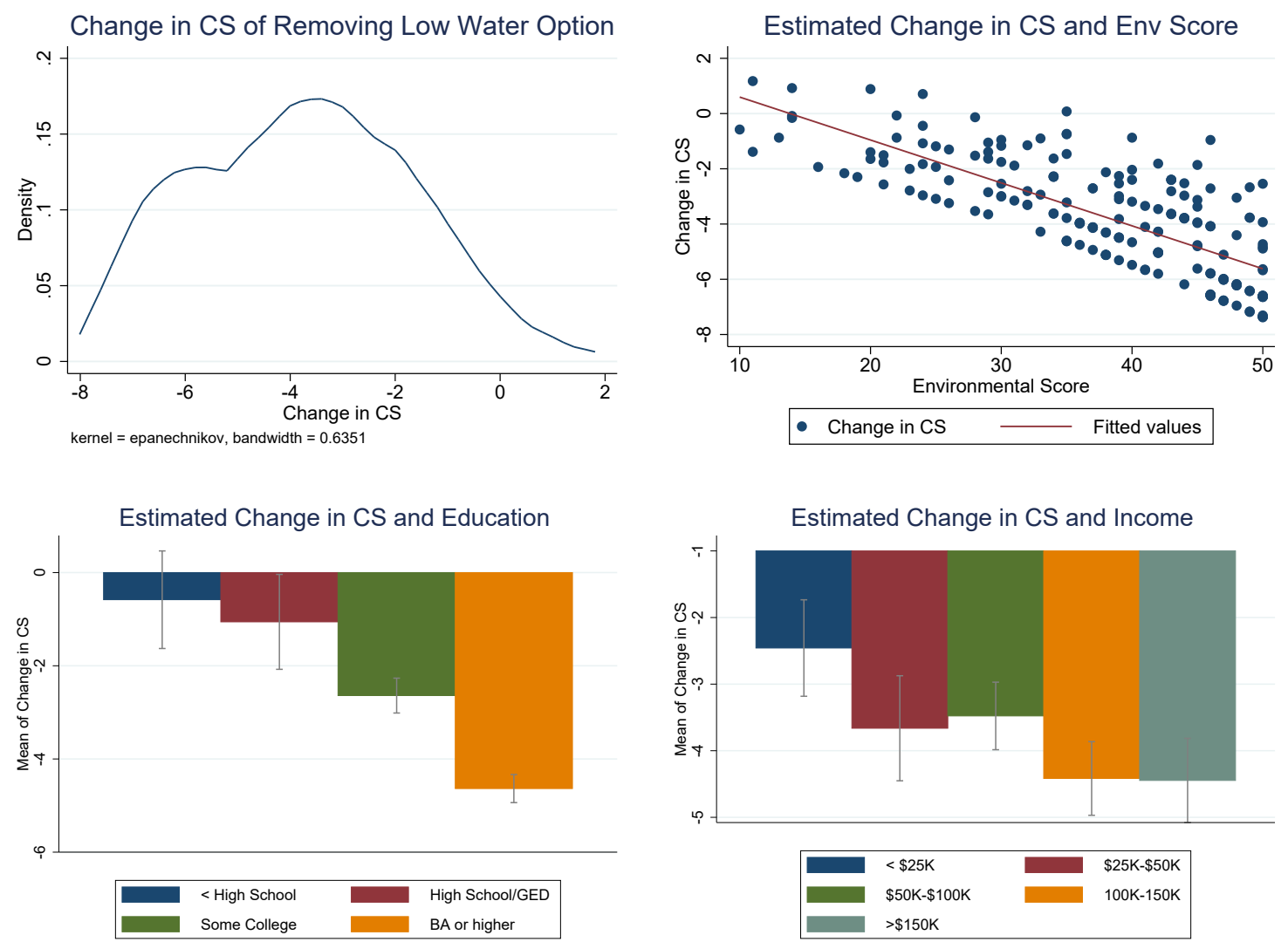

Note: The figure displays the kernel density of the distribution of changes in consumer surplus (CS) with and without the LWF attribute. Estimates based on mixed logit choice specification. Education is considered into four ranges: Less than high school degree; High school degree or equivalent (e.g., GED); Some college or Associate degree; and Bachelor degree or Graduate degree. Income is classified into 5 ranges: Less than $\$ 25,000 ; \$ 25,000-49,999 ; \$ 50,000-\$ 99,999, \$ 100,000-149,999$, and $\$ 150,000$ or more. 
Figure 4: Estimated Probability of Choosing Alternatives, With and Without Low Water Attribute and for Net Welfare Losers and Non-losers
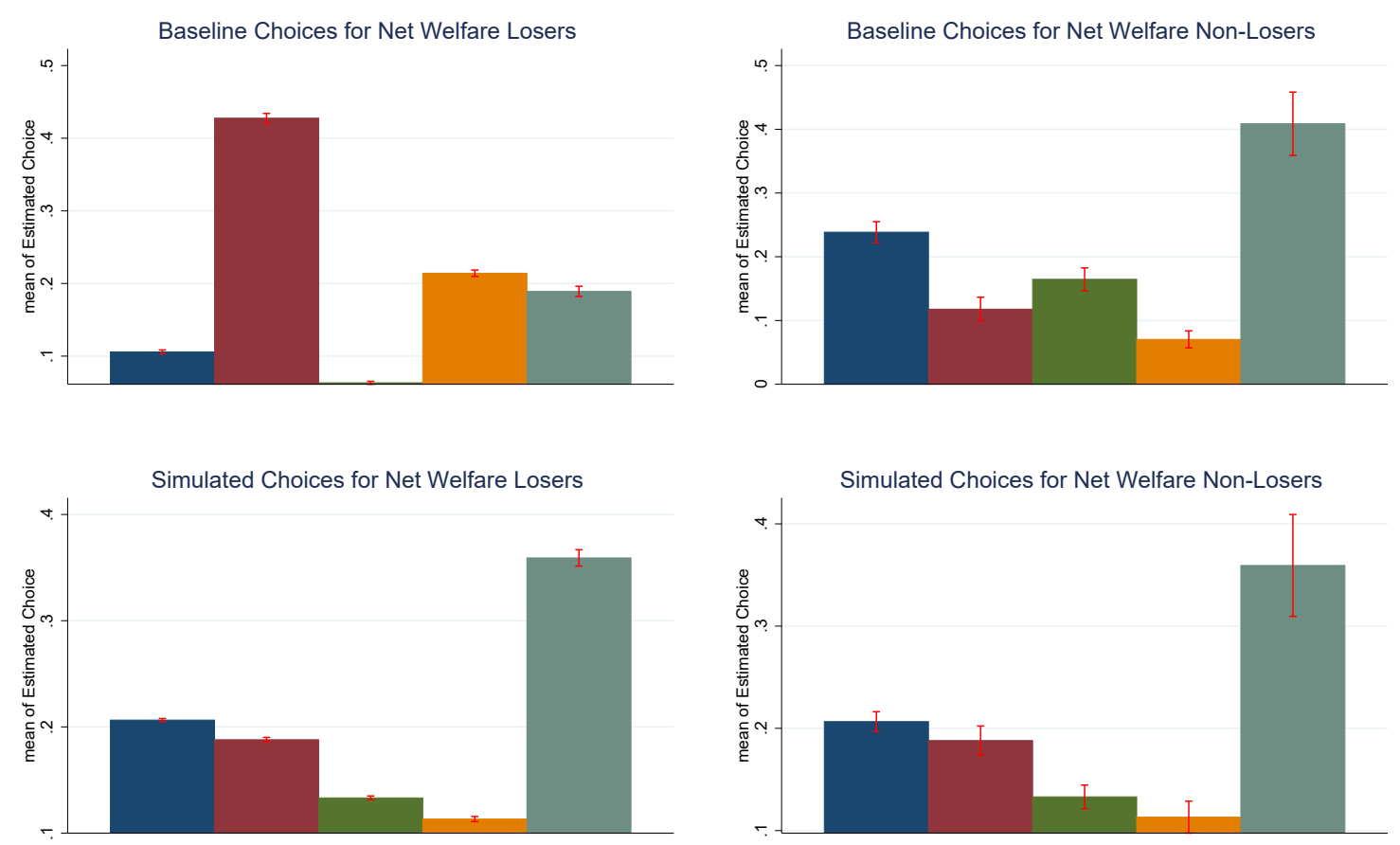

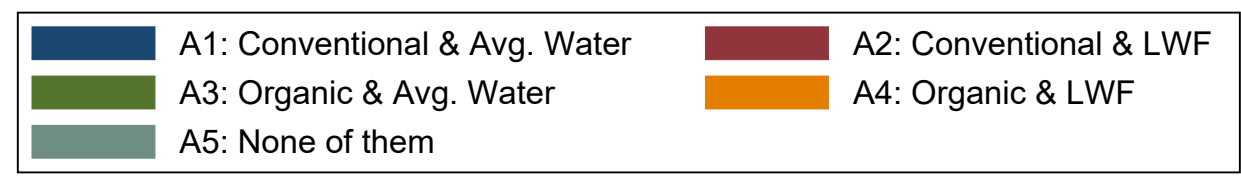

Note: The figure displays the average estimated probabilities, and confidence intervals, of choosing the 5 alternatives with the LWF attribute (baseline top panels) and without LWF attribute (simulated bottom panels). Estimates based on the random coefficients mixed logit choice specification for net welfare losers (left panels) and non-losers (right panels). The five alternatives are: (1) conventional and average water; (2) conventional and low water; (3) organic and average water; (4) organic and low water; (5) none of them. 
Figure 5: Histograms of Changes in Consumer Surplus, for the Survey Sample (red) and for the Survey Sample Re-Weighted to the California Distribution of Demographics (blue)
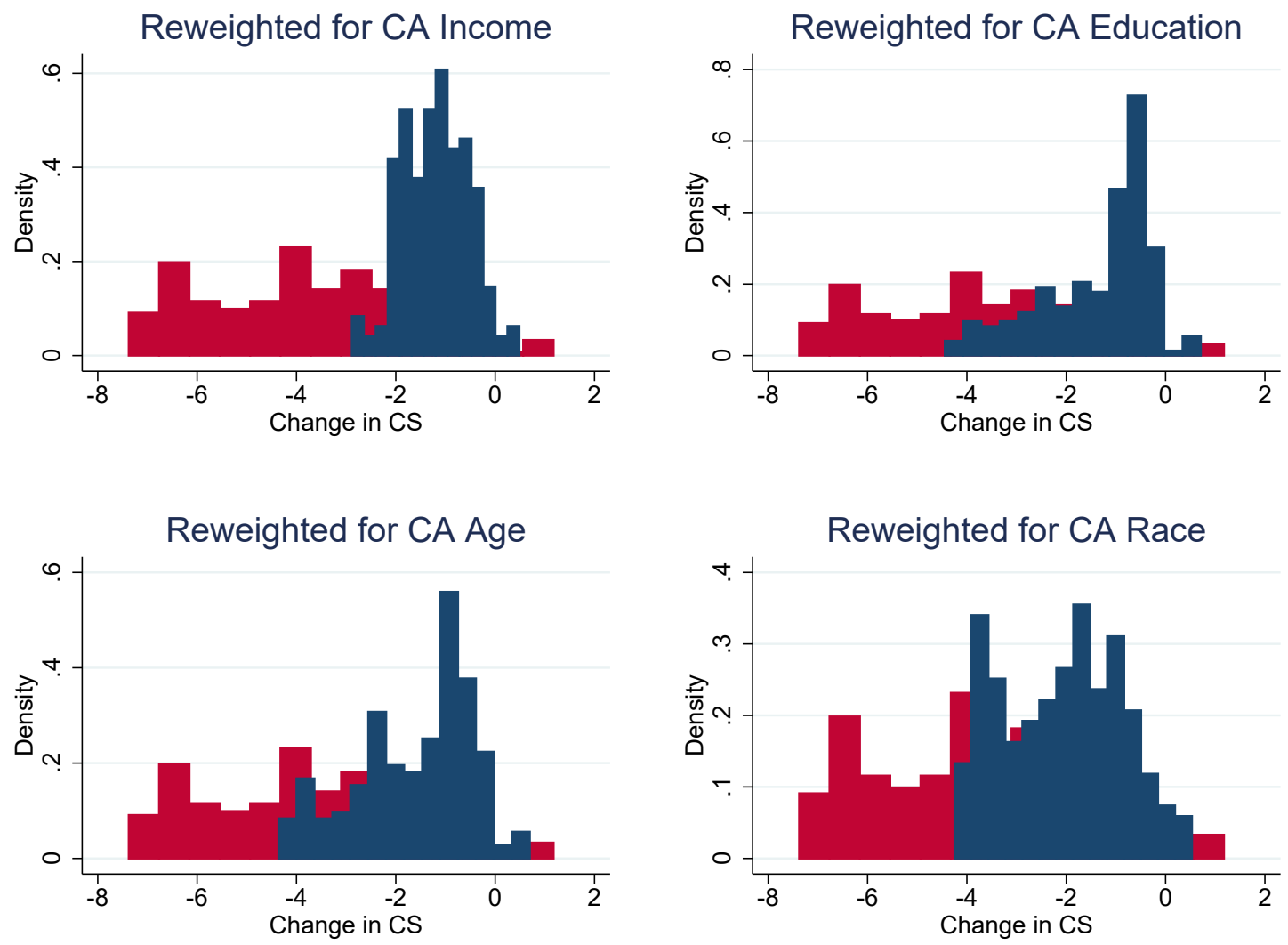

Note: The figure displays the sample histogram of the respondents' changes in consumer surplus due to the counterfactual simulation of removing the LWF option, depicted in red. In blue, we overlap the histogram of the estimated changes in consumer surplus where we re-weight the sample to match the California distribution of Income (top left), Education (top right), Age (bottom left), and Race (bottom right), based on the random coefficients mixed logit choice specification. Estimates based on mixed logit choice specification. 
A Appendix Figures 
Figure A.1: Survey Instrument Page 1

Survey for CA Choices
thank you for participating in this survey.
"Required
What is your gender *
male
female
30-39
40-49-29
18-59 or older
Bachelor degree
graduate degree

What is your household income *

Mark only one oval.

less than $\$ 25,000$

$\$ 25,000$ to $\$ 49,00$

$\$ 50,000$ to 75,000

$\$ 75,000$ to $\$ 100,000$

$\$ 100,000$ to $\$ 125,000$

$\$ 125,000$ to $\$ 150,000$

$\$ 150,000$ or more

What is your race

Mark only one oval.

White
Hispanic
Black or African American
Asian
American Indian
Other:

Climate change is a result of human activities and is already affecting people

wark only one oval.

$\begin{array}{lllllll}1 & 2 & 3 & 4 & 5 & \\ \text { Strongly Disagree } \square & \square & \square & \square & \square & \end{array}$

Protecting the environment should be given utmost priority, even if it causes slower economic growth and some loss of jobs. Mark only one oval.

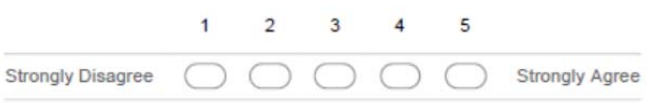

It is the government's responsibility to impose high taxes on fossil fuels. Mark only one oval.

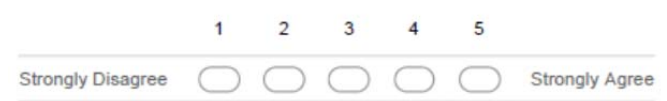

The U.S. government should impose stricter laws on pollution.

Mark only one oval.

$\begin{array}{ccccccc} & 1 & 2 & 3 & 4 & 5 & \\ \text { Strongly Disagree } & \square & \square & \square & \square & \bigcirc & \text { Strongly Agree }\end{array}$

People should pay higher prices to address climate change.

Mark only one oval.

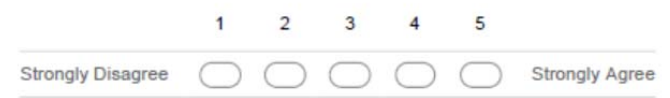

There should be more investment using tax dollars in alternative fuels. " Mark only one oval.

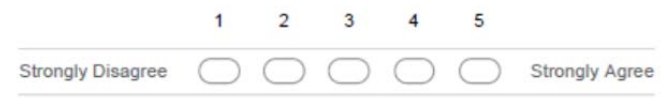

People should make lifestyle changes to reduce environmental damage. Mark only one oval.

$\begin{array}{lcccccc} & 1 & 2 & 3 & 4 & 5 & \\ \text { Strongly Disagree } & \bigcirc & \bigcirc & \bigcirc & \bigcirc & \text { Strongly Agree }\end{array}$ 
Figure A.2: Survey Instrument Page 2

It is important to purchase things that are more environmentally friendly, even at a greater cost.

$\begin{array}{lllllll} & 1 & 2 & 3 & 4 & 5 & \\ \text { Strongly Disagree } & \bigcirc & \bigcirc & \bigcirc & \bigcirc & \text { Strongly Agree }\end{array}$

The current generation has a responsibility to protect the environment for future The curation gevertion

Mark only one oval.

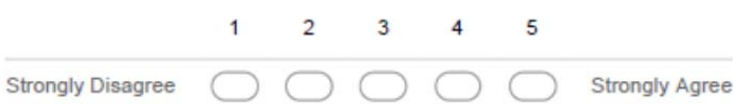

Personal food choices can affect the environmental impact of agriculture Mark only one oval.

$\begin{array}{lllllll} & 1 & 2 & 3 & 4 & 5 & \\ \text { Strongly Disagree } & \square & \square & \square & \square & \text { Strongly Agree }\end{array}$

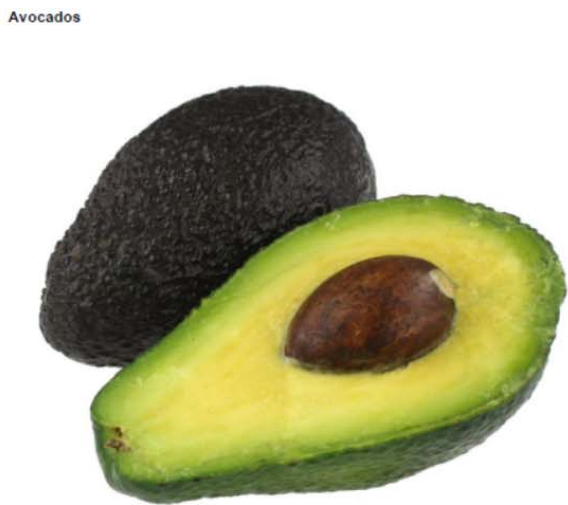

Mark only one oval.

S0.98 Lb, conventional, Average Water footpint of 157 gallons per $L$ L

52.00/L organic, Average Water Footprint of 157 gallons per Lb

S1.18/Lb Conventional, Effcient Water Footprint, 80 gallons per

\$2.40 Lb, Organic Efficient Water Footprint, 80 gallons per Lb

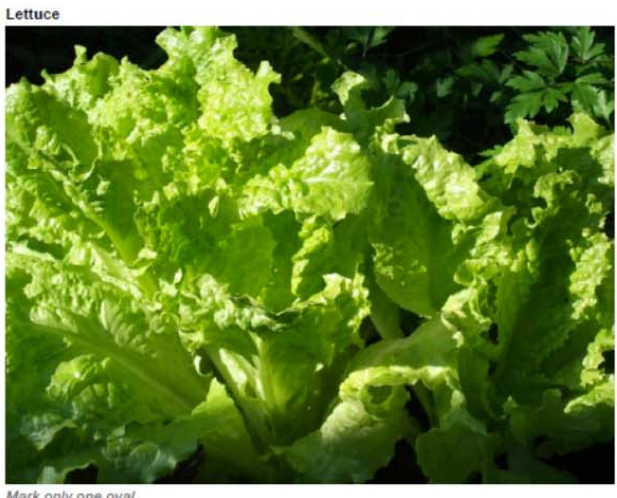

S2.17 Lb, conventional, Average Water footprint of 14.8 gallons per L

$\$ 5.00$ Lb organic, Average Water Footprint of 14.8 gallons per L $L$

$\$ 2.60 \mathrm{Lb}$ Conventional, Efficient Water Footprint, 5.9 gallons per L

S6.00 Lb, Organic Efficient Water Footprint, 5.9 gallons per L Lb

I would not purchase any of these

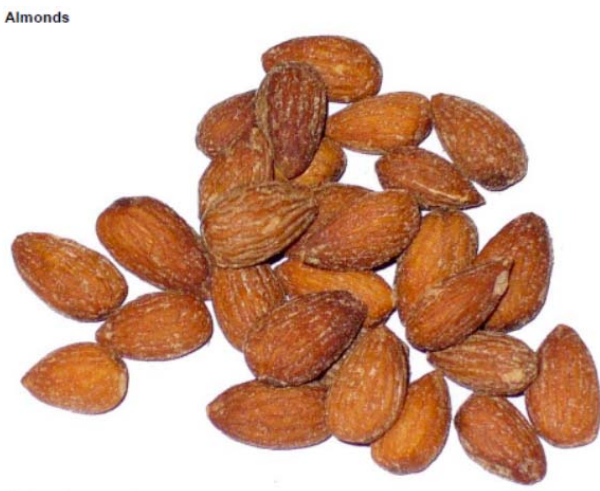

Mark only one oval.

$\$ 5.99 \mathrm{Lb}$, conventional, Average Water footpint of 1.715 gallons per $L$

$\$ 11.59$ Lb organic, Average Water Footprint of 1,715 gallons per L L

\$7. 19 Lb Conventional, Efficient Water Footorint 1.450 gallons per L

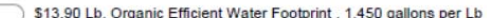

I would not purchase any of these

Tomato

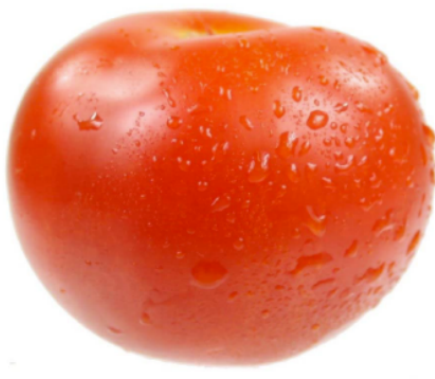

Mark only one oval.

$\$ 1.56 \mathrm{Lb}$, conventional, Average Water footprint of 16.9 gallons per L L

S1.99 Lb organic, Average Water Footprint of 16.9 gallons per $L$ b

$\$ 2.39$ Lb Conventional, Efficient Water Footprint, 6.5 gallons per L L

$\$ 1.87 \mathrm{Lb}$, Organic Efficient Water Footprint, 6.5 gallons per $L \mathrm{~b}$

I would not purchase any of these 
Figure A.3: Average Respondent Characteristics for Treatment and Control Groups
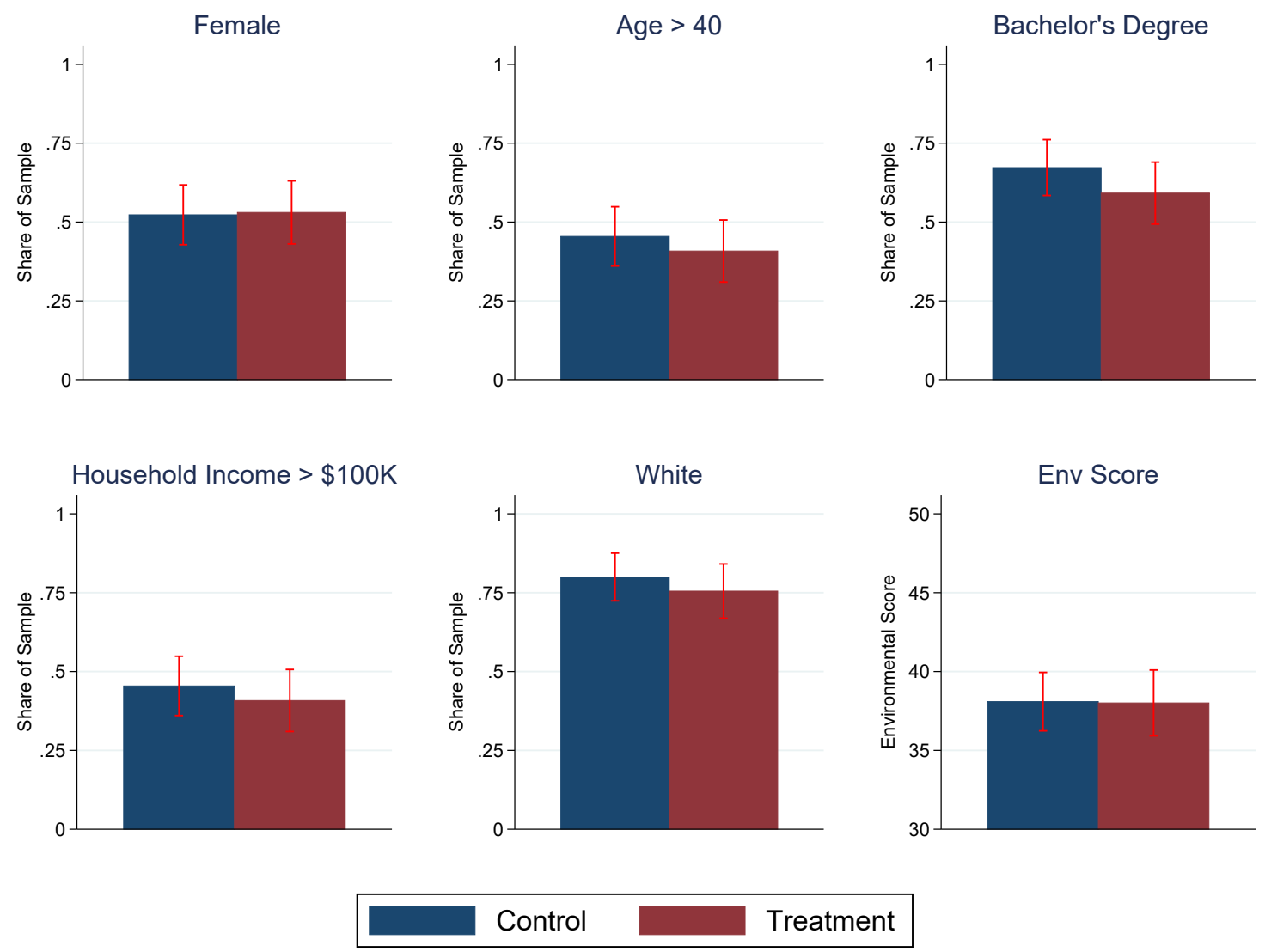

Note: The figure displays the average demographic characteristics of respondents, for the control and for the treatment groups separately. Environmental Score has a minimum value of 10 if a respondent strongly disagreed with all ten of the environmental statements and a maximum of 50 if the respondent strongly agreed with all of the same ten statements. Source: Survey. N=208 observations. 


\section{Figure A.4: Kernel Density Estimates and Test of Distribution Equality}
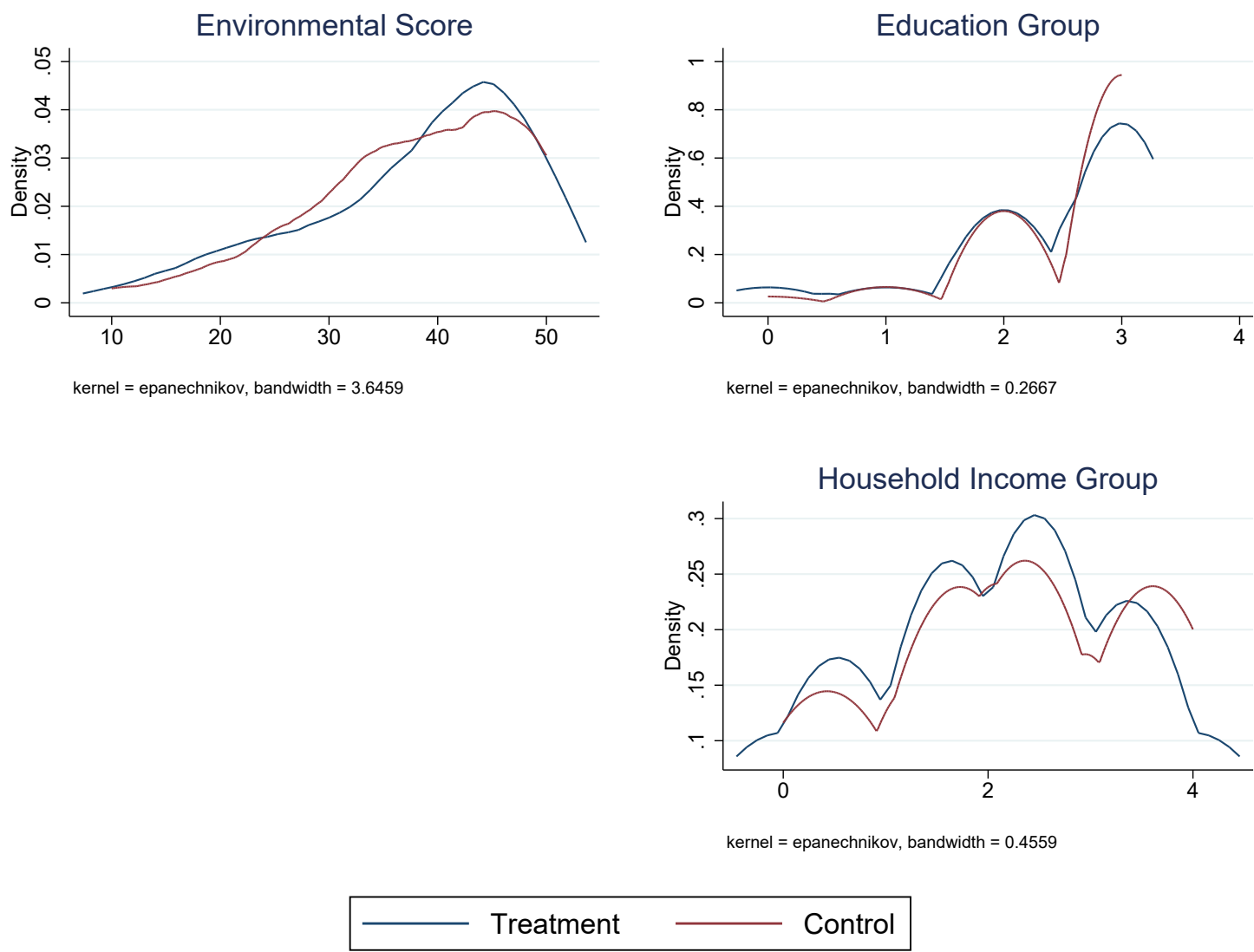

Note: The figure displays the kernel density estimates of characteristics of respondents for the control and for the treatment groups separately and tests for equality using the Kolmogorov-Smirnov test.

Kolmogorov-Smirnov test for equal distribution (p-values in parentheses): Environmental Score $=0.075(0.943)$; Education $=$ 0.0748 (0.936); Income $=0.1183$ (0.481). Source: Survey. N=208 observations. 